Article

\title{
Defining an Ecologically Ideal Shallow Groundwater Depth for Regional Sustainable Management: Conceptual Development and Case Study on the Sanjiang Plain, Northeast China
}

\author{
Xihua Wang ${ }^{1,2,3}$, Guangxin Zhang ${ }^{1,3, *}$, Yi Jun $\mathrm{Xu}^{4}$ and Xiangjun Shan 5 \\ 1 Northeast Institute of Geography and Agroecology, Chinese Academy of Sciences, \\ Changchun 130102, China; E-Mail: wangxihua342@163.com \\ 2 University of the Chinese Academy of Sciences, Beijing 100049, China \\ 3 Key Laboratory of Wetland Ecology and Environment, Northeast Institute of Geography and \\ Agroecology, Chinese Academy of Sciences, Changchun 130102, China \\ 4 School of Renewable Natural Resources, Louisiana State University Agricultural Center, \\ 227 Highland Road, Baton Rouge, LA 70803, USA; E-Mail: yjxu@1su.edu \\ 5 Northeast Electric Power Design Institute Co., Ltd. of China Power Engineering Consulting Group, \\ Changchun 130033, China; E-Mail: xiangjun.shan@gmail.com \\ * Author to whom correspondence should be addressed; E-Mail: zhgx@iga.ac.cn; \\ Tel.: +86-0431-8554-2210; Fax: +86-0431-8554-2298.
}

Received: 21 April 2015 / Accepted: 6 July 2015 / Published: 21 July 2015

\begin{abstract}
The depth and fluctuation of shallow groundwater influence water supply to land surface vegetation. Knowledge of an ecologically ideal depth range of shallow groundwater for a vegetation ecosystem can be crucial for sustainability of regional water resource management and ecological conservation. In this study, we developed a conceptual model that identifies an upper and a lower boundary of shallow groundwater for sustaining present vegetation ecosystems, termed ecologically ideal shallow groundwater depth (EISGD). We then applied the conceptual model to the Sanjiang Plain $\left(10.9 \times 10^{4} \mathrm{~km}^{2}\right)$ in northeast China in order to gain insights into sustainable shallow groundwater usage in this intensively irrigated agricultural region. Using soil capillary rise, plant rooting depth, extinction depth, and the actual groundwater depth, we identified an upper boundary range of EISGD between 0.5 and $2.8 \mathrm{~m}$ and a lower boundary range of EISGD between 2.0 and $14.3 \mathrm{~m}$ for different vegetation covers in the Sanjiang Plain. Based on the ranges, we estimated allowable shallow groundwater withdrawal (i.e., without degrading the present vegetation ecosystem) for the region and identified an area of $2.54 \times 10^{10} \mathrm{~m}^{2}$ with a total of $9.14 \times 10^{8} \mathrm{~m}^{3}$ water deficit.
\end{abstract}


Currently, the entire Sanjiang Plain has a total volume of $45.30 \times 10^{8} \mathrm{~m}^{3}$ EISGD allowable shallow groundwater withdrawal, thus the plain's northeast region can be considered as having a high allowable pumping capacity. This study demonstrates that application of an EISGD concept can be useful for developing regional management strategies and plans for ecological protection and sustainable groundwater utilization.

Keywords: ecohydrogeology; shallow groundwater; soil-water interaction; groundwater evaporation; water resources management; ecological protection; Sanjiang plain

\section{Introduction}

The depth and fluctuation of shallow groundwater (SG) (usually $<30 \mathrm{~m}$ ) influence water availability to terrestrial ecosystems. Different SG depths support different vegetation communities, creating a diverse landscape [1-6]. Knowledge of the range of ideal SG depths for diverse vegetation covers provides important information for protecting both the ecosystem and sustainable water resources management at the landscape scale.

The importance of SG depth for vegetation growth, composition, and structure has long been recognized. Many studies have shown that the growth of woody plants and herbaceous species are greatly affected by shallow groundwater depth and its fluctuation [7-13]. In a recent study, Lowry et al. [14] found that shallow groundwater depth could also control vegetation composition and patterning in mountain meadows. In a study on the global pattern of shallow groundwater table in relation with wetlands and vegetation types, Fan et al. [13] found that shallow groundwater influenced $22 \%$ to $32 \%$ of the global land area, one third to half of which was vegetated land surface. Satchithanantham et al. [15] reported that $92 \%$ of the water used for potato cultivation in southern Manitoba was from shallow groundwater. From their study on the interactions between groundwater, surface water, and riparian vegetation at the lower Tarim River in northwest China, Schilling et al. [16] reported an inverse linear relationship of tree ring growth to the depth to groundwater.

In order to assess the availability of groundwater for vegetative ecosystems, several researchers introduced a term for a specific shallow groundwater depth that is ideal for supporting certain surface vegetation. Zhang et al. [17] suggested a regional ecological groundwater table (EGWT) in a range of 2-10 $\mathrm{m}$ for the Huabei Plain in China, one of the largest alluvial plains in the world. Based on their field observations, Zhang et al. [18] proposed an EGWT (from 3 to $10 \mathrm{~m}$ ) for the Haihe Valley in east China and Sun et al. [19] recommended an EGWT from 2 to $17 \mathrm{~m}$ for different areas in the Sanjiang Plain in northeast China. For the arid region in northwest China Brunner et al. [20,21] developed an approach to generate maps of phreatic evaporation and subsequent soil salinization using remote sensing and stable isotopes. Sun et al. [22] made an estimation of ecological water demand for the lower Liaohe River Plain in north China, and Sun et al. [23] made an estimation based on an empirical range assumption of the capillary rise of a phreatic surface. Rong et al. [24] explored several methods to estimate EGWT for the lower Tarim River Basin in the arid region of west China and suggested an ideal shallow ground depth of 4-6 m. Xin et al. [25] argued that an EGWT should be undertaken whenever a region needs to develop a groundwater pumping plan. Collectively, these studies introduced the idea and necessity of developing 
ecologically ideal groundwater depths for vegetation ecosystems. However, none of them considered spatial distribution of vegetation types across the landscape while making a suggestion for ideal regional shallow groundwater depth. Also, the studies often used empirical judgment and arbitrary assumptions to make estimates for EGWT, making it difficult to evaluate their validity. In general, a well-defined concept for an ecologically ideal groundwater table is lacking. Such an ecologically-based hydrogeological concept can be useful for developing practical management plans to protect groundwater resources and the environment.

Different vegetation types have different intensive rooting depths. Information on the spatial variability of vegetation is crucial for determining the ecologically ideal groundwater depth. Theoretically, a similar plant ecosystem could exist in places under different groundwater depths (e.g., many conifer trees species). This is because climatic factors, such as precipitation and evapotranspiration, affect water supply as well. However, a plant ecosystem may shift if the present shallow groundwater depth drastically changes. In the past several decades, shallow groundwater depths in many regions of the world have been reported to have decreased largely due to intensive agriculture and urbanization-for instance, in the Sanjiang Plain, northeast China [26]; in the High Plain (Ogallala Aquifer), Central USA [27,28]; and in East Anglia, England [29]. The knowledge of a threshold boundary of shallow groundwater for certain vegetation covers can be critical for developing integrated management strategies and plans to support regional ecosystem protection, sustainable agriculture, and groundwater resources management. It is, therefore, of relevance to both scientific research and management practices to develop a simple, useful method for identifying ecologically ideal shallow groundwater depths (EISGD).

The Sanjiang Plain is one of China's most important grain production regions with a total arable land of $3.67 \times 10^{4} \mathrm{~km}^{2}$. It is also the largest inland freshwater wetland region in China, with a total wetland area of $1.14 \times 10^{4} \mathrm{~km}^{2}$ [30]. Annually, a total of $2.57 \times 10^{9} \mathrm{~m}^{3}$ of groundwater is used for agriculture irrigation in the Sanjiang Plain, which accounts for $60 \%$ of the total groundwater pumpage in the region [31]. Continuous use of a large quantity of groundwater has generated concerns, as researchers found a considerable drop in the regional shallow groundwater. For instance, Zhao et al. [26] reported a 5-m decline of the shallow groundwater level in the central Sanjiang Plain and a large area of cone of depression in the northwest Sanjiang Plain over the past 50 years. The large usage of groundwater in the region, together with the large-area conversion of wetlands for rice cultivation over the past three decades, has been also reported to have an impact on surface water [32,33] and groundwater quality [34], due probably to an accelerated interaction between the surface water (rivers and wetlands) and groundwater. With the shallow groundwater depth dropping, the region has experienced wetland degradation across a large area. Song et al. [35] reported that, in total, about $80 \%$ of the wetlands in the Sanjiang Plain disappeared since the 1960s. Collectively, these issues raise serious concerns over the long-term development of regional agriculture, economy, and environmental health. Management strategies and plans are needed to protect the region's groundwater resources and wetlands. As a first step, it is important to identify a spatially explicit groundwater range that is ecologically ideal in supporting current vegetation covers in the region. This knowledge can be very helpful for local water resources management and ecosystem preservation efforts.

To our best knowledge, no studies have been done in identifying an ecologically ideal shallow groundwater depth. While the studies mentioned above [17-25] were successful in making a connection between shallow groundwater and vegetation growth in each particular region, they did not include 
developing a specialized, and potentially universal, method for separating climate- and soil-related effects from vegetation dependency on shallow groundwater. In general, a specific theoretical concept and a well-outlined quantitative approach are lacking. In this study, we developed a concept for defining the depth range of shallow groundwater that is necessary for sustaining present vegetation ecosystems, termed "ecologically ideal shallow groundwater depth" (EISGD). We then applied the approach to the Sanjiang Plain in northeast China to assess EISGDs for several major vegetation covers in the region.

\section{Study Area}

Covering a total land area of $10.9 \times 10^{4} \mathrm{~km}^{2}$, the Sanjiang Plain is located in Heilongjiang Province, northeast China (Figure 1). It is a large alluvial floodplain formed in the lower reach of three rivers, the Songhua, Heilong, and Wusuli (Sanjiang in Chinese literally means three rivers). The Heilong and Wusuli Rivers are international rivers draining China's and Russia's territorial lands with an annual average yield of 346.5 billion $\mathrm{m}^{3}$ and 61.9 billion $\mathrm{m}^{3}$, respectively. Flowing across the Sanjiang Plain in China, the Songhua River yields a long-term annual average of 72.7 billion $\mathrm{m}^{3}$ [26].

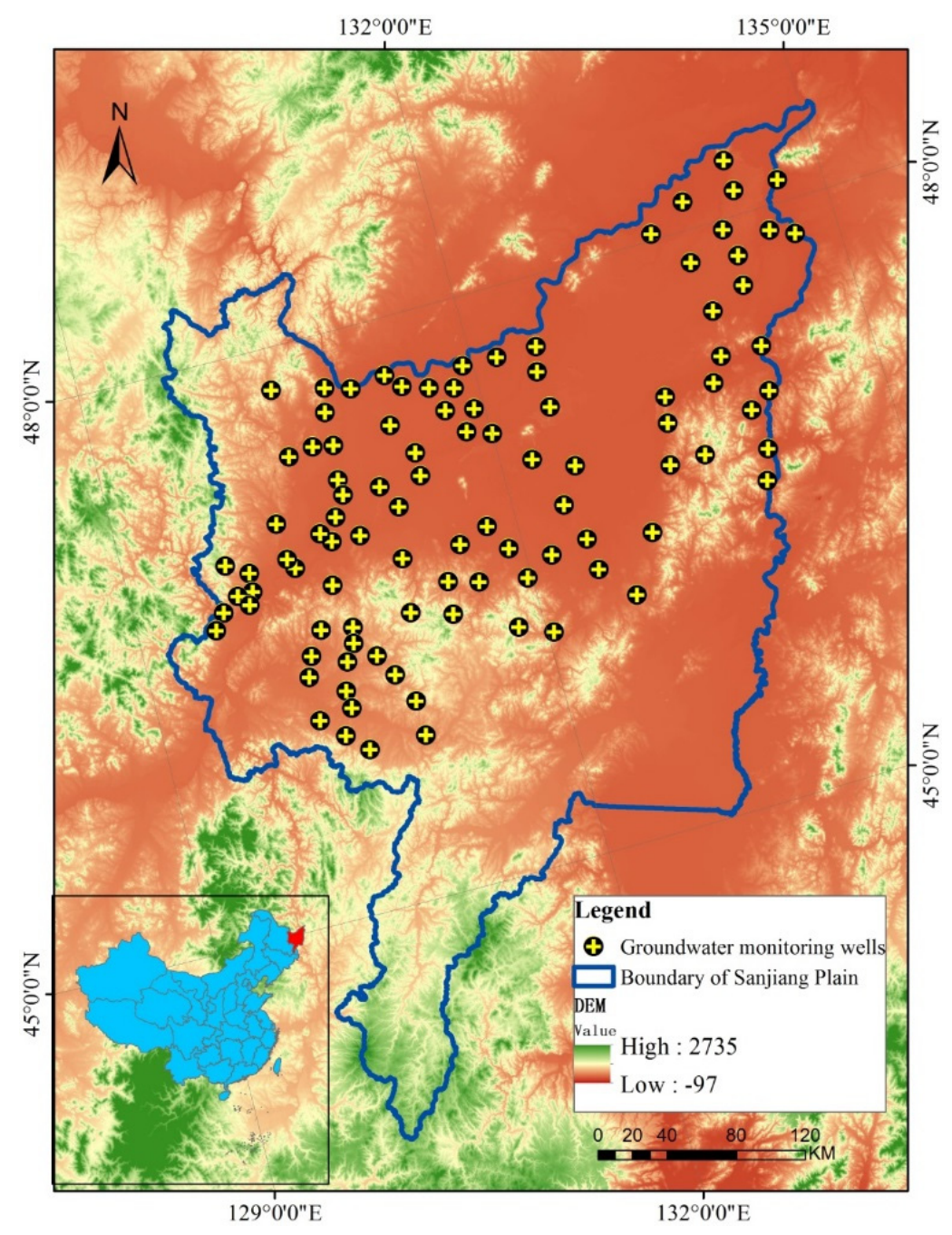

Figure 1. Geographical location of the Sanjiang Plain in Heilongjiang Province, northeast China, and the groundwater monitoring well sites used in this study. 
The climate of this region can be characterized as temperate continental monsoon, with a long-term annual average temperature of $2.8^{\circ} \mathrm{C}$ and an annual average precipitation of 500-650 mm, more than $60.0 \%$ of which occurs within the three months from June to August [36]. The topography of this region is flat and much of the region is located on a floodplain with a slope gradient between $0.01 \%$ and $0.02 \%$. The west edge and southeast edge of the Sanjiang Plain are the Xiaoxinganling Mountain and the Wanda Mountain with elevations of $1429 \mathrm{~m}$ a.s.1. and $831 \mathrm{~m}$ a.s.l., respectively. The region is largely covered by Quaternary alluvial sediments (loam), where the major mining layers of groundwater are located. Based on the geological age, geomorphology, lithology, and burial depth, the aquifer formations can be classified as (1) quaternary loose deposits of sand gravel pore water formation; (2) tertiary sandstone siltstone interlayer pore water formation; and (3) quaternary bedrock fissure water formation. The aquifer materials consist of loam, fine sand, medium sand, sandy clays, and silts [26].

Vegetation covers of the Sanjiang Plain have changed considerably in the past decade. In the past half century, a large area of wetlands has been converted into agricultural farmland [35]. In the past 10 years, the area of woodland, meadow, and wetlands has further decreased by $0.58 \%, 12.53 \%$, and $4.41 \%$, respectively, whereas the land areas for rice paddies increased by $2.08 \%$ [36]. In addition, some areas of soil in the Sanjiang Plain have become salinized, and the degree of salinity is high. With a large quantity of shallow groundwater being pumped annually for irrigation, the trend of salinity qualification increases [37]. Currently, major land use/land cover types in the Sanjiang Plain include wetland, rice paddy, crop upland, woodland, and meadow. The wetlands occupy $9.2 \%$ (or $1.00 \times 10^{4} \mathrm{~km}^{2}$ ), the arable land (sum of rice paddy and cropland) $53.6 \%$ (or $5.57 \times 10^{4} \mathrm{~km}^{2}$ ), the woodland $33.1 \%$ (or $3.40 \times 10^{4} \mathrm{~km}^{2}$ ), and the meadows $4.1 \%$ (or $0.40 \times 10^{4} \mathrm{~km}^{2}$ ) [35,38]. Rice is the dominant crop in the region.

\section{Methodology}

\subsection{Conceptual Framework of an Ecologically Ideal Shallow Groundwater Depth (EISDG)}

In this study, we propose to use capillary rise, extinction depth of shallow groundwater evaporation, and rooting depth to determine an upper boundary and a lower boundary of shallow groundwater for a certain vegetation type (Figure 2). The concept of determining the boundaries for an ecologically ideal shallow groundwater depth is based on preservation of the present vegetation. When shallow groundwater level rises to the surface or near-surface, plant roots switch to an anoxia environment. Most xeric plants cannot tolerate extended period of saturation $[39,40]$. In addition, if the surface soil is rich in salt, rising of shallow groundwater level may lead to surface salt accumulation in some climate regions degrading soil quality $[41,42]$. On the other hand, when the shallow groundwater level declines to deeper depths, it becomes inaccessible to plant roots and groundwater transpiration is nearly zero [43]. Over a long period of time with shallow groundwater decline, surface vegetation communities (e.g., farmland, woodland, meadow, and wetlands) will degrade or shift to different communities. 


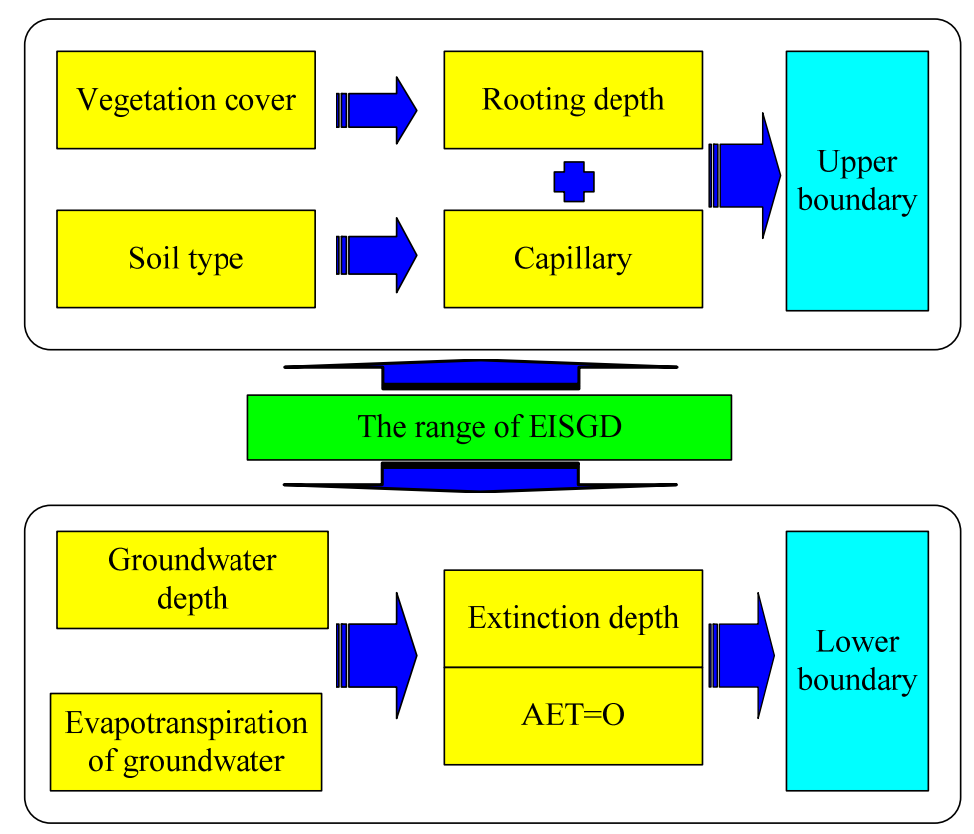

Figure 2. Flow chart of the conceptual model for determining ecologically ideal shallow groundwater depth (EISGD).

\subsubsection{Determining the Upper Boundary of EISGD}

For some vegetation types, in particular upland farmland, a change in shallow groundwater depth is related to capillary rise and plant root uptake. If the shallow groundwater depth rises enough, it would possibly accumulate salts in the upper soil layer in regions with high soil salt contents, which can be detrimental to vegetation. For those regions, it is ideal that shallow groundwater depth does not frequently rise up above the height reachable through capillary rise and plant root uptake. Thus, we define the sum of capillary rise height and rooting depth as the upper shallow groundwater boundary depth (Figure 3). The height of capillary rise can be obtained using the visual method by measuring the wetting front of a soil column. Lago and Araujo [44] used this method (a vertical capillary tube) to obtain the capillary rise height in porous media. Fries et al. [45] used the same method to calculate the capillary rise height and obtained a satisfactory result.

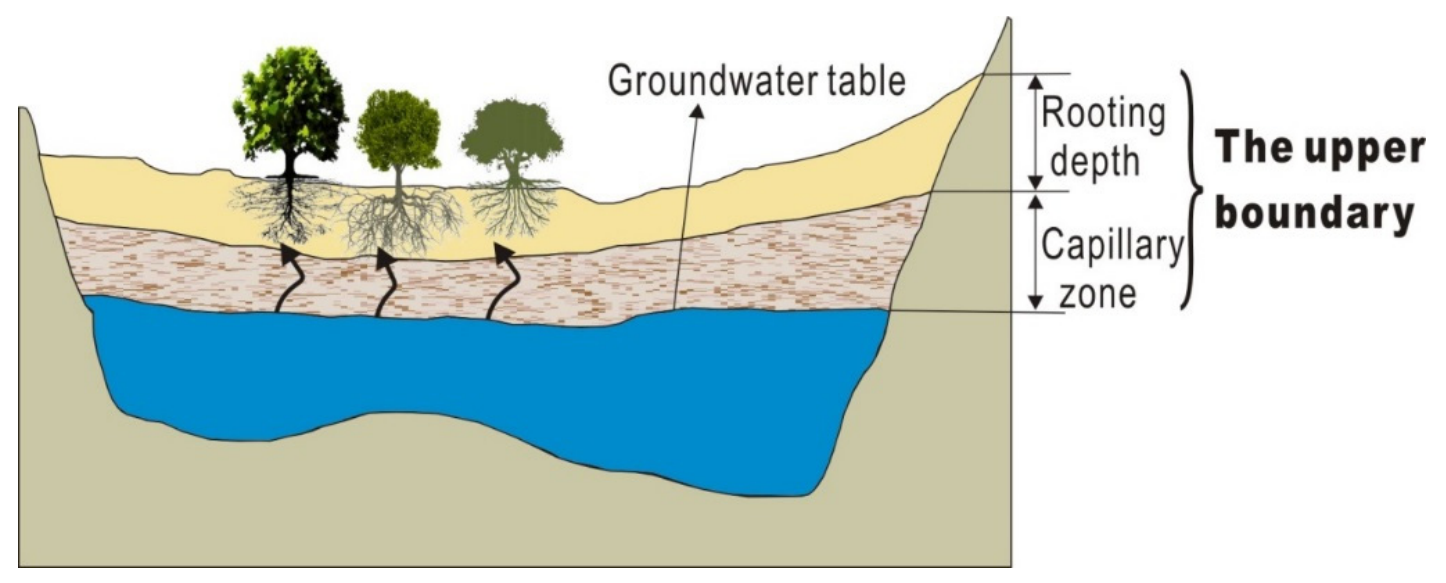

Figure 3. Diagram showing the conceptual upper groundwater boundary that is crucial to the stability of a present vegetation system. 
The height and velocity of capillary rise are a function of time [45] (Figure 4a). If the velocity of capillary rise is steady-state, the height of corresponding point of time (Figure $4 \mathrm{~b}, t_{\mathrm{m}}$ ) can be considered as the maximum of CRHP (Figure $4 \mathrm{a}, h_{\mathrm{m}}$ ).

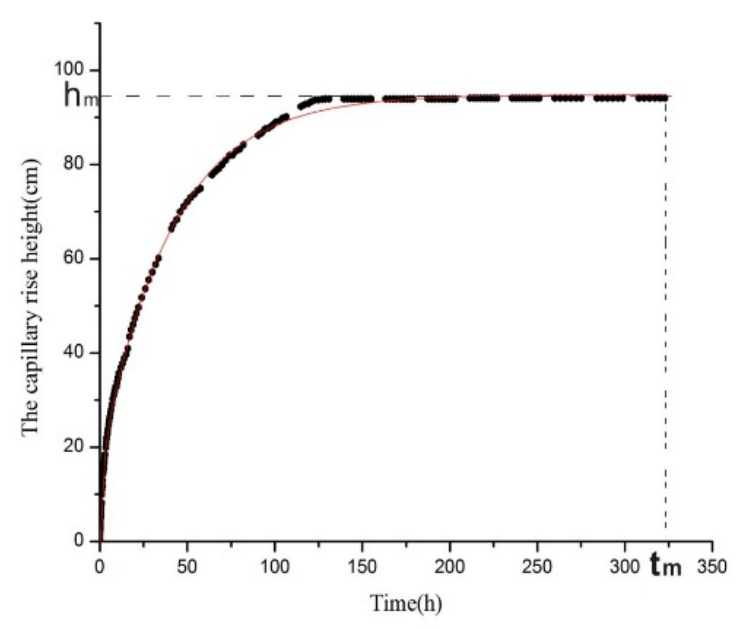

(a)

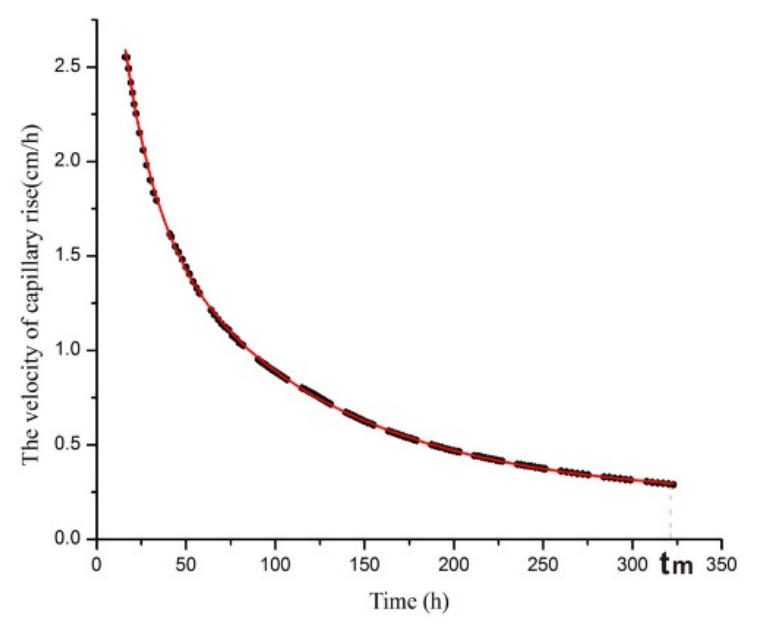

(b)

Figure 4. Schematic diagram of the capillary rise height (a) and the velocity of capillary rise (b).

\subsubsection{Determining the Lower Boundary of EISGD}

The survival and growth of vegetation can be affected by shallow groundwater depth and its fluctuation. Therefore, the shallow groundwater depth should sustain a certain range; the deepest line where the evaporation of groundwater is zero, beyond which it would lead to the vegetation degradation or shift, we defined as the lower boundary of EISGD (Figure 5). The lower boundary of EISGD is expressed in the form of extinction depth, which can be estimated with Averianov, S' equation [46,47]. Sun et al. [21] found Averyanov's equation very useful and applied it to estimate the extinction depth of phreatic surface for the lower Liaohe River Plain in northeast China.

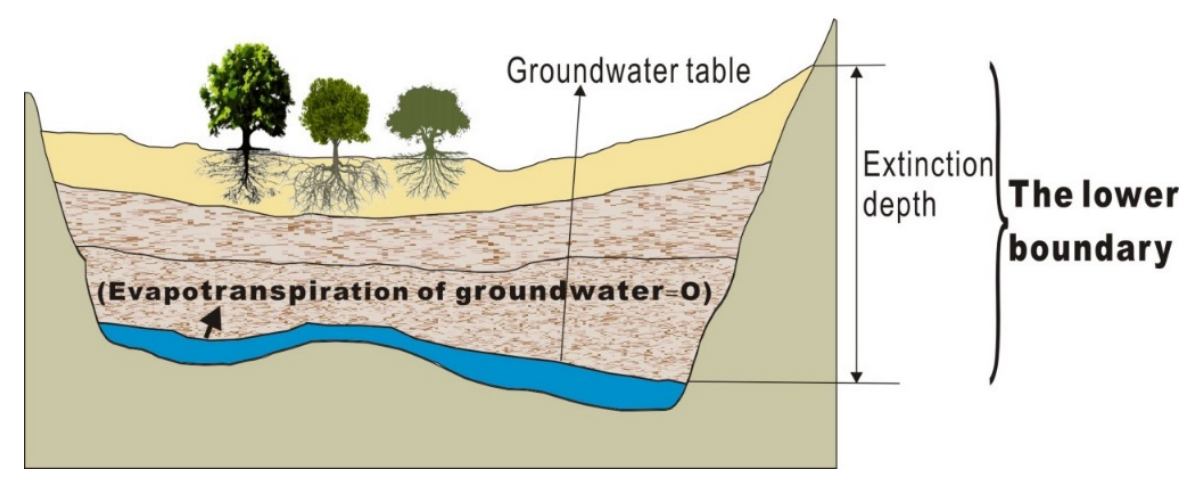

Figure 5. Diagram showing the conceptual lower groundwater boundary that is crucial to the stability of a present vegetation system.

To calculate extinction depth, three time points need to be identified on a groundwater fluctuation curve (Figure 6) during which no or minimal precipitation occurs. We obtained the slope $(i)$ and groundwater depth $(h)$ of each point. 


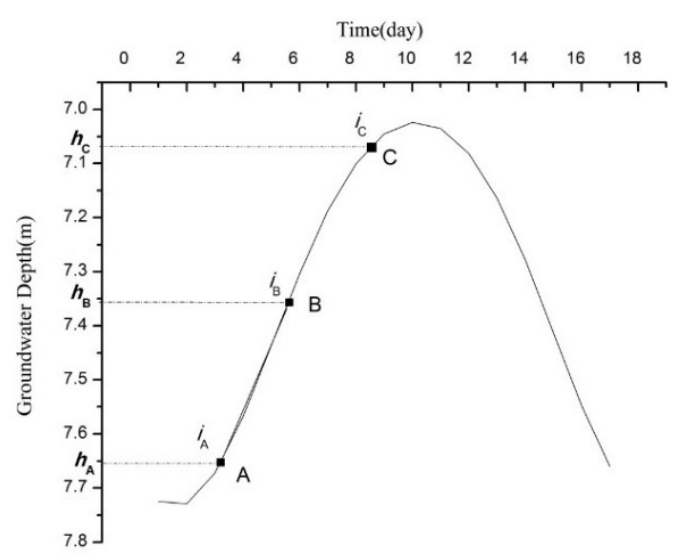

(a)

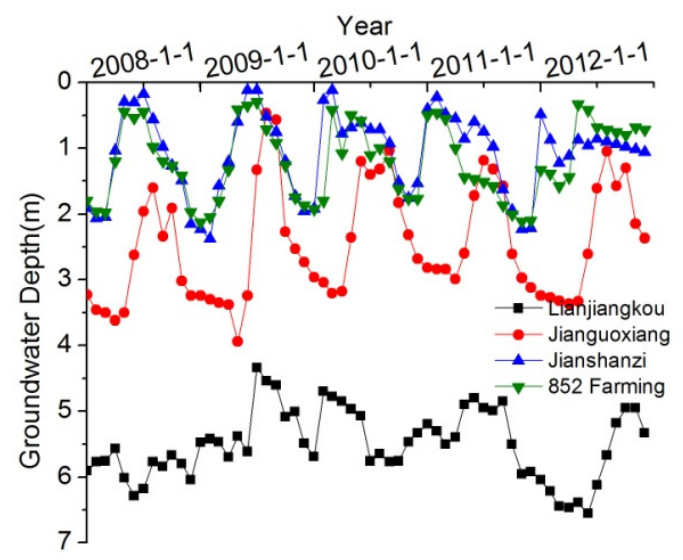

(b)

Figure 6. (a) Schematic diagram of a shallow groundwater depth fluctuation curve, whereby $i$ and $h$ are the slope and groundwater depth of each point, respectively; (b) Shallow groundwater depths of four representative wells on the Sanjiang Plain, Northeast China.

$$
A E T=\mu \frac{d h}{d t}=E_{p a n}\left(1-\frac{h}{L}\right)^{n}
$$

$A E T$ is the actual evaporation, $E_{\text {pan }}$ is the potential evaporation, $L$ is the extinction depth (groundwater depth where evapotranspiration is zero), and $\mu$ is the specific yield.

When identifying the time points in the groundwater depth fluctuation curve (Figure 6), the following requirements have to be met:

$$
\frac{h_{1}}{h_{2}}=\frac{h_{2}}{h_{3}}
$$

Using $\frac{d h}{d t}$ to replace the $i$, we then obtained the following equation:

$$
\mu i=E_{\mathrm{pan}}\left(1-\frac{h}{L}\right)^{n}
$$

The following equation can be obtained for each point based on Equation (3):

$$
\left\{\begin{array}{l}
\mu i_{1}=E_{\mathrm{pan}}\left(1-\frac{h_{1}}{L}\right)^{n} \\
\mu i_{2}=E_{\mathrm{pan}}\left(1-\frac{h_{2}}{L}\right)^{n} \\
\mu i_{3}=E_{\mathrm{pan}}\left(1-\frac{h_{3}}{L}\right)^{n}
\end{array}\right.
$$

By transforming the above equations the following can be obtained:

$$
\left\{\begin{array}{l}
1-\left(\frac{\mu i_{1}}{E_{\text {pan }}}\right)^{\frac{1}{n}}=\frac{h_{1}}{L} \\
1-\left(\frac{\mu i_{2}}{E_{\text {pan }}}\right)^{\frac{1}{n}}=\frac{h_{2}}{L}
\end{array}\right.
$$


Equation (6) can be obtained by putting one equation divided by another one, aiming to obtain $\frac{h_{1}}{h_{2}}$ :

$$
\frac{1-\left(\frac{\mu i_{1}}{E_{\mathrm{pan}}}\right)^{\frac{1}{n}}}{1-\left(\frac{\mu i_{2}}{E_{\mathrm{pan}}}\right)^{\frac{1}{n}}}=\frac{h_{1}}{h_{2}}
$$

Putting $\frac{h_{1}}{h_{2}}=a$ into Equation (6), Equation (7) can be derived:

$$
1-\left(\frac{\mu i_{1}}{E_{\mathrm{pan}}}\right)^{\frac{1}{n}}=a-a\left(\frac{\mu i_{2}}{E_{\mathrm{pan}}}\right)^{\frac{1}{n}}
$$

Meanwhile, we also can obtain the following equation:

$$
1-\left(\frac{\mu i_{2}}{E_{\mathrm{pan}}}\right)^{\frac{1}{n}}=a-a\left(\frac{\mu i_{3}}{E_{\mathrm{pan}}}\right)^{\frac{1}{n}}
$$

Then we can obtain the following equation by combining Equations (7) and (8):

$$
\left(\frac{\mu i_{2}}{E_{\mathrm{pan}}}\right)^{\frac{1}{n}}-\left(\frac{\mu i_{1}}{E_{\mathrm{pan}}}\right)^{\frac{1}{n}}=a\left(\frac{\mu i_{3}}{E_{\mathrm{pan}}}\right)^{\frac{1}{n}}-a\left(\frac{\mu i_{2}}{E_{\mathrm{pan}}}\right)^{\frac{1}{n}}
$$

$\left(\mu / E_{\mathrm{pan}}\right)^{\frac{1}{n}}$ was divided by the two sides of equation, we obtained the following Equation (10):

$$
(1+a) \cdot\left(i_{2}\right)^{\frac{1}{n}}=\left(i_{1}\right)^{\frac{1}{n}}+a\left(i_{3}\right)^{\frac{1}{n}}
$$

Therefore, we can obtain the value of $n$.

According to Equation (4), Equation (11) can be obtained:

$$
\left(\frac{i_{1}}{i_{2}}\right)^{\frac{1}{n}}=\frac{L-h_{1}}{L-h_{2}}
$$

Putting $b=\left(\frac{i_{2}}{i_{1}}\right)^{\frac{1}{n}}$ into Equation (11), finally we obtain the extinction depth of phreatic surface as shown below:

$$
L=\frac{h_{2}-b h_{1}}{1-b}
$$

\subsection{Data Collection}

We collected the most recent years' records on shallow groundwater depths across the Sanjiang Plain (Figure 1). The data, obtained from the Jiamusi Bureau of Hydraulics, included depth measurements of 102 wells over the period from 2008 to 2013. Groundwater depths in these wells were recorded with an automatic water level recorder (Odyssey, Dataflow Co., Christchurch, New Zealand). In this study, we 
used groundwater levels recorded on the 1th, 6th, 11th, 16th, 21th, and 26th days of each month for six years from 2008 to 2013 . The shallow groundwater depths from 2008 to 2012 were used to calculate the extinction depth, and the average groundwater depths in 2013 was used to evaluate the groundwater storage condition [38].

To estimate evaporation of phreatic surface, we collected climatic data recorded at eight national weather stations in the region. The data were obtained from the Chinese Meteorological Data Sharing Service System and covered a period from 1958 to 2011. When calculating the evaporation of phreatic surface, potential evaporation rates based on the meteorological data were estimated and applied to the corresponding regions.

\subsection{Field Survey and Sampling}

To determine the capillary rise of 18 major soil types in the Sanjiang Plain, soil sampling was conducted at 54 sites across the region (Figure 7). At each site a 150-cm deep profile was dug (Figure 7) in order to collect samples from $0-\mathrm{cm}, 20-\mathrm{cm}, 40-\mathrm{cm}, 60-\mathrm{cm}, 80-\mathrm{cm}, 100-\mathrm{cm}$, and 150-cm depths (Figure 7). Composite samples were made from three sites of a same soil type.
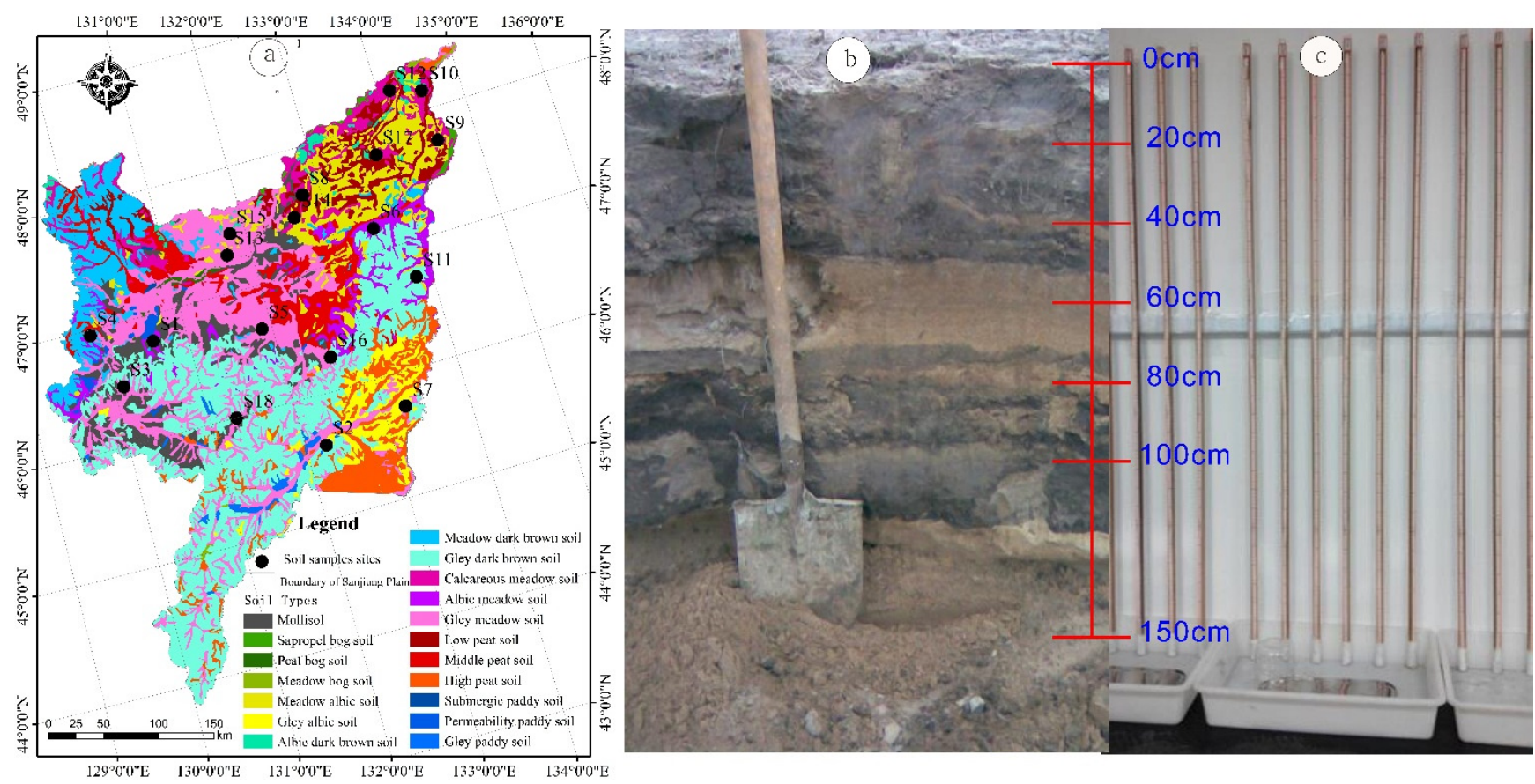

Figure 7. Soil sampling locations and soil types in the Sanjiang Plain (a); soil profile (b); and vertical tubes used for measuring capillary rise (c).

Soil samples from different sites and depths were air-dried in the shade, ground, and sieved through a 2-mm sieve. Each of the samples was filled into a 160-cm long tube with a diameter of $2 \mathrm{~cm}$ (Figure 7). The tubes were installed vertically. Capillary rise heights of different sites in the tubes were recorded (Figure 8), as well as the capillary rise velocity (Figure 9). If capillary rise velocity was less than $0.005 \mathrm{~cm} / \mathrm{h}$, the height of correspond point of time was considered as the maximum capillary rise of phreatic surface (CRHP) for the soil sample. 


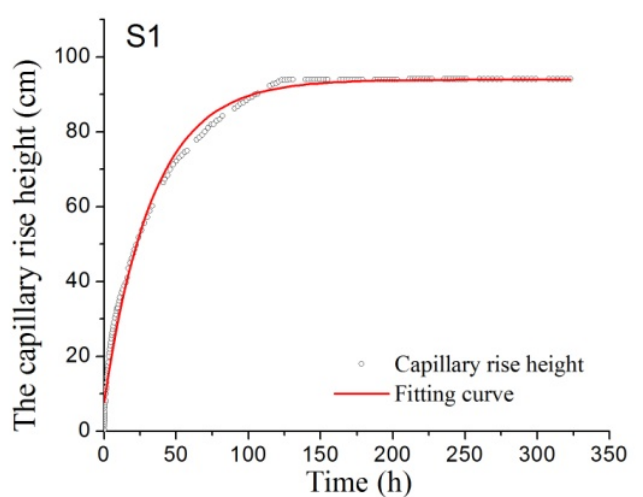

(a)

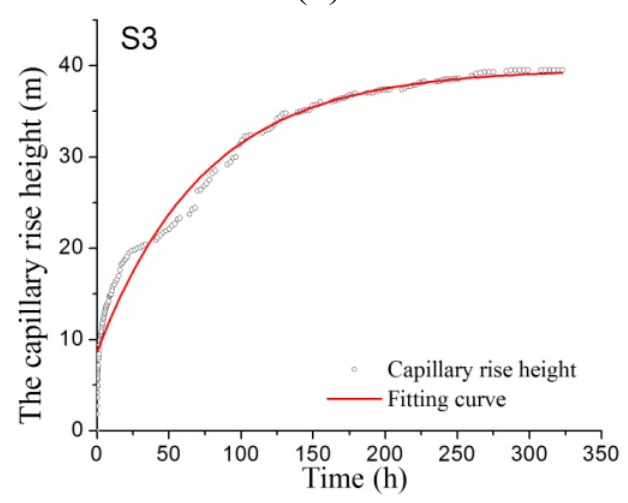

(c)

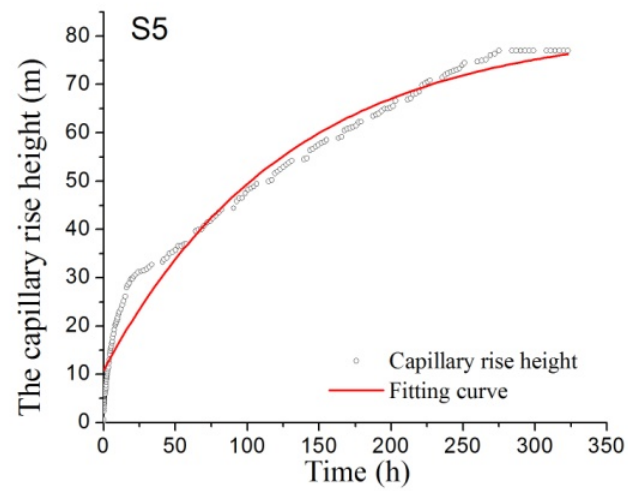

(e)

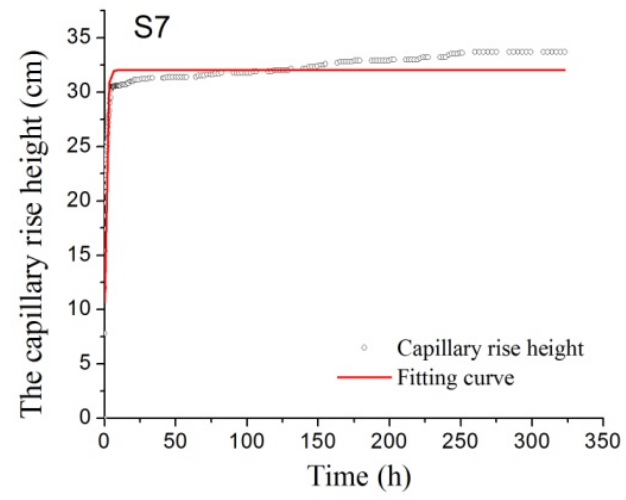

(g)

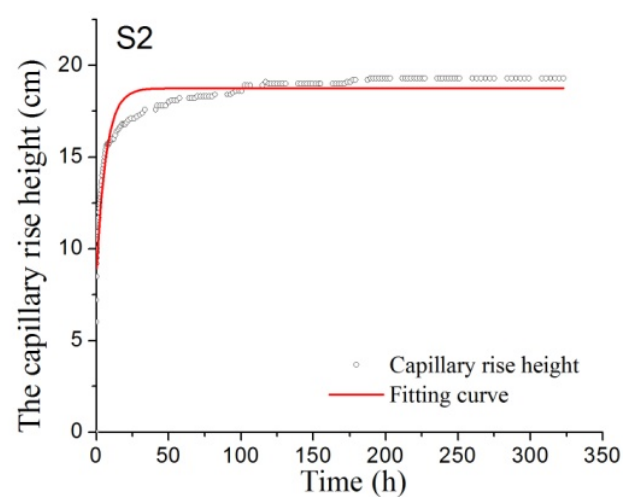

(b)

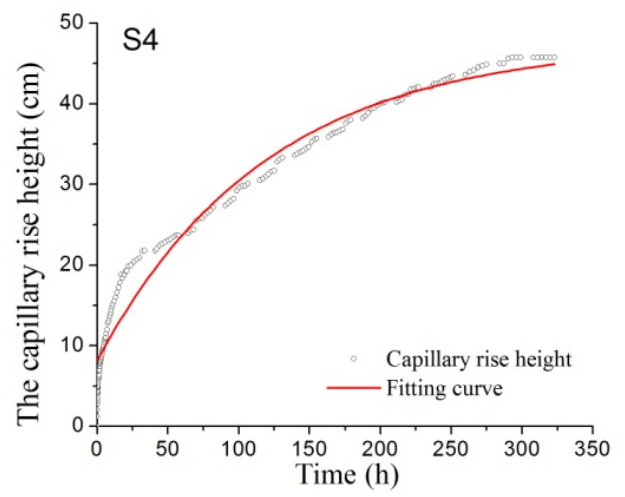

(d)

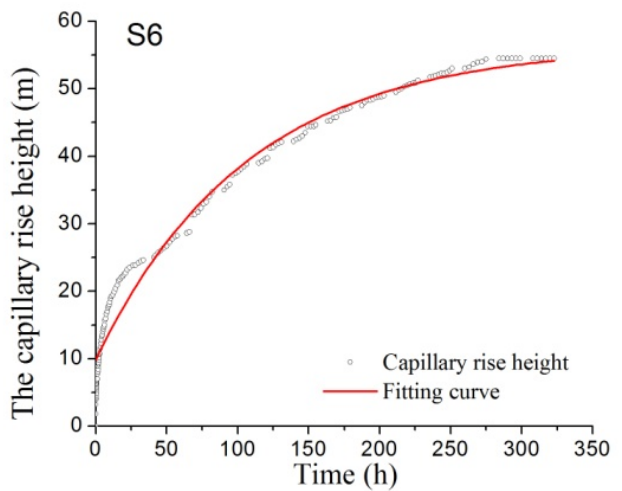

(f)

2.00

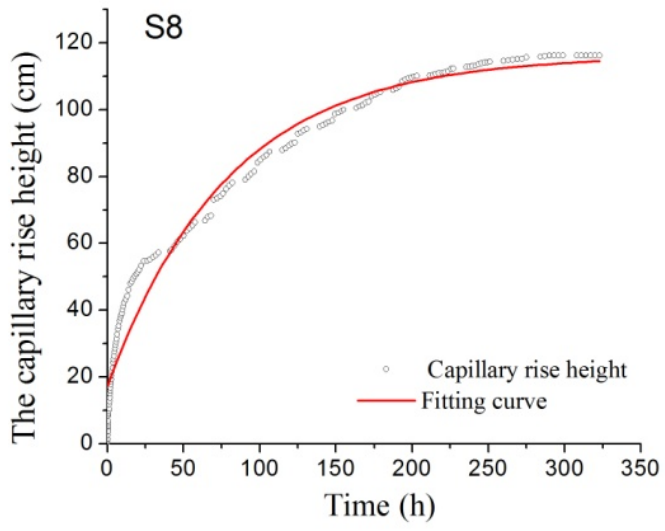

(h)

Figure 8. Cont. 


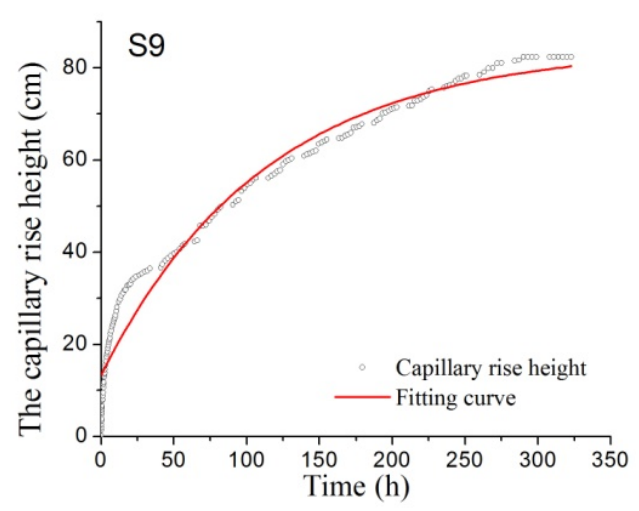

(i)

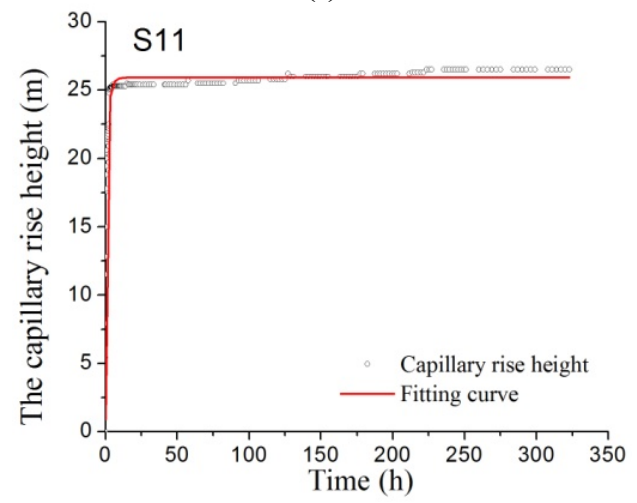

(k)

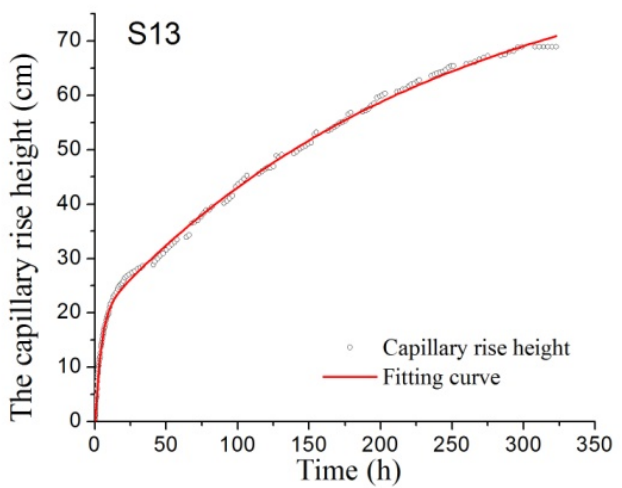

(m)

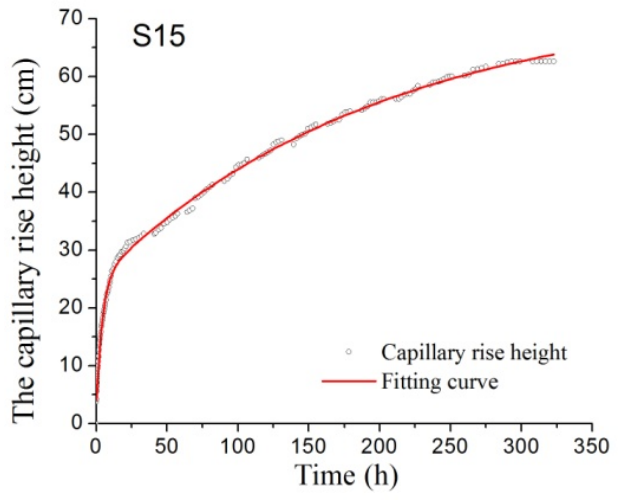

(o)

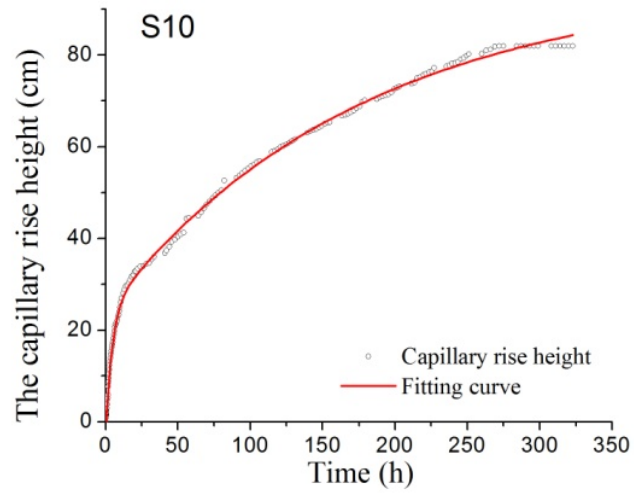

(j)

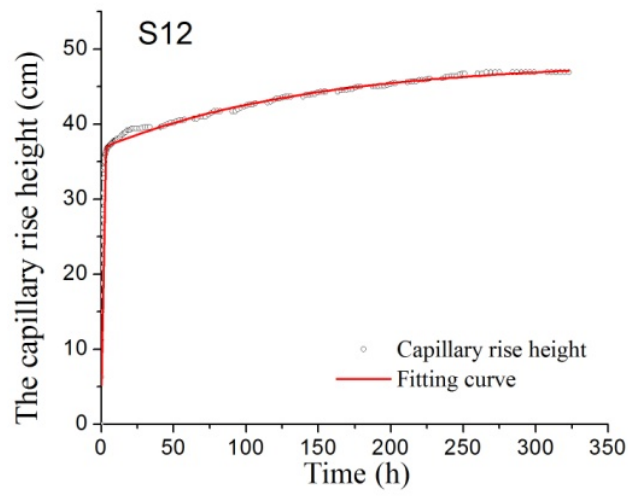

(l)

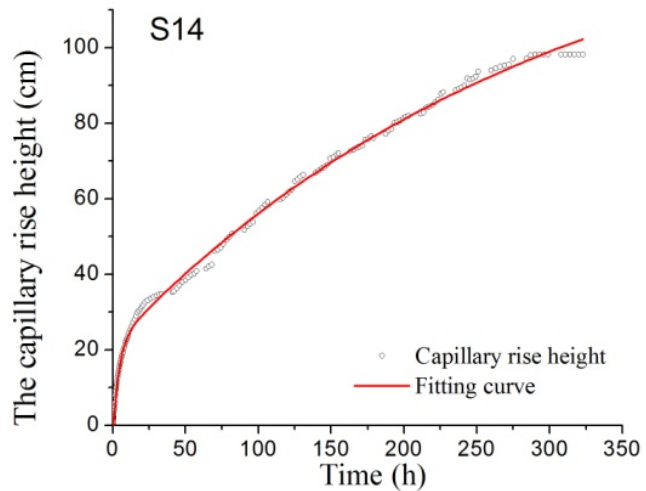

(n)

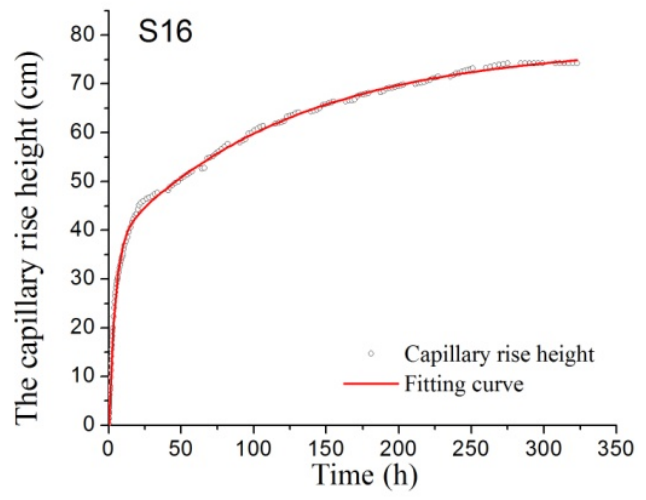

(p)

Figure 8. Cont. 


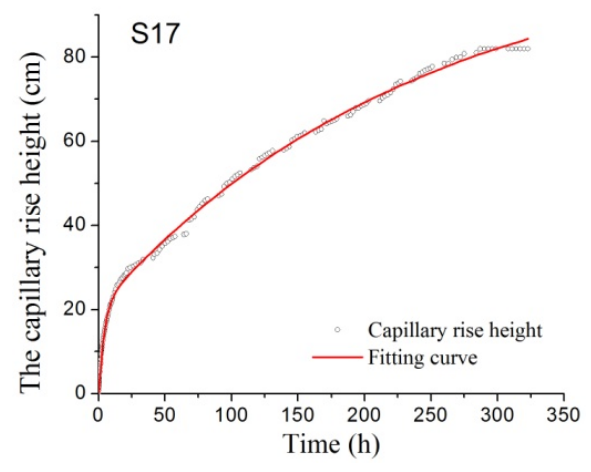

$(\mathbf{q})$

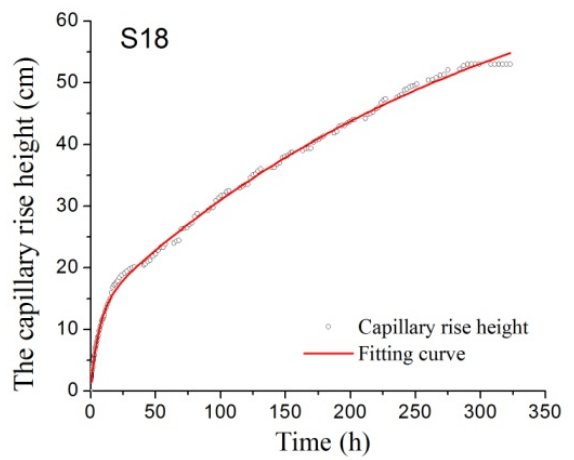

$(\mathbf{r})$

Figure 8. Capillary rise of 18 major soil types in the Sanjiang Plain, Northeast China. (a) S1; (b) S2; (c) S3; (d) S4; (e) S5; (f) S6; (g) S7; (h) S8; (i) S9; (j) S10; (k) S11; (l) S12; (m) S13; (n) $\mathrm{S} 14 ;$ (o) $\mathrm{S} 15 ;$ (p) $\mathrm{S} 16 ;$ (q) $\mathrm{S} 17 ;$ (r) $\mathrm{S} 18$.

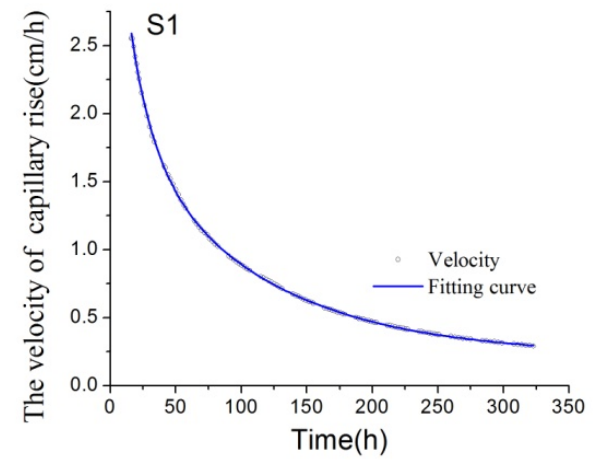

(a)

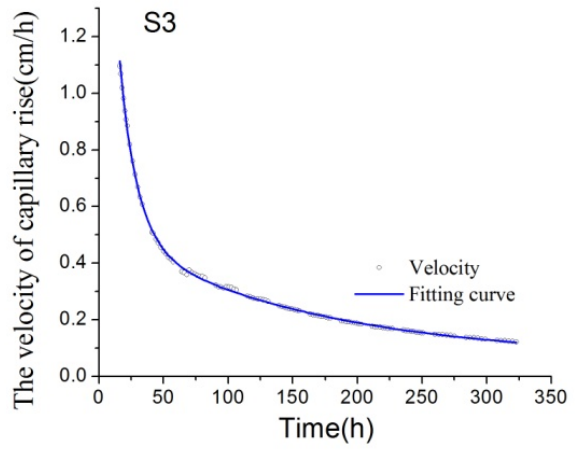

(c)

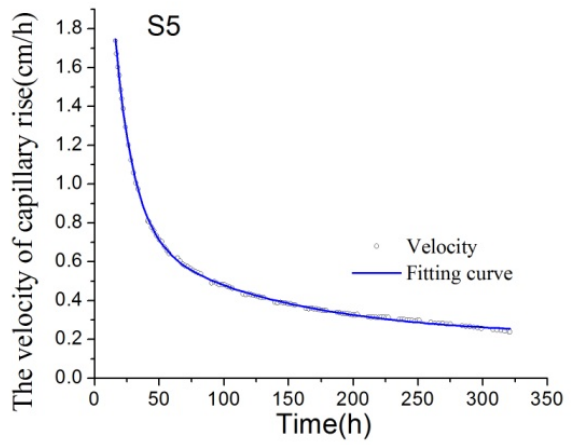

(e)

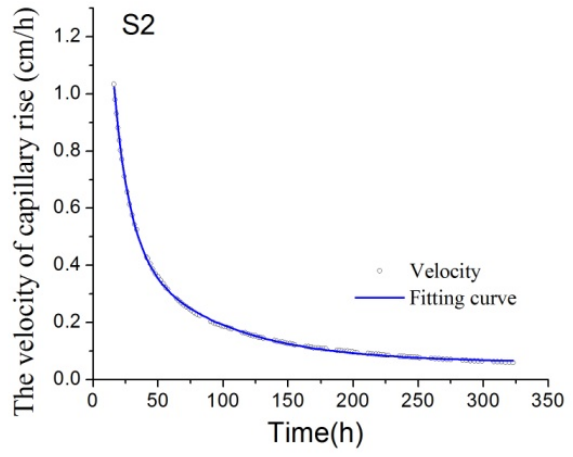

(b)

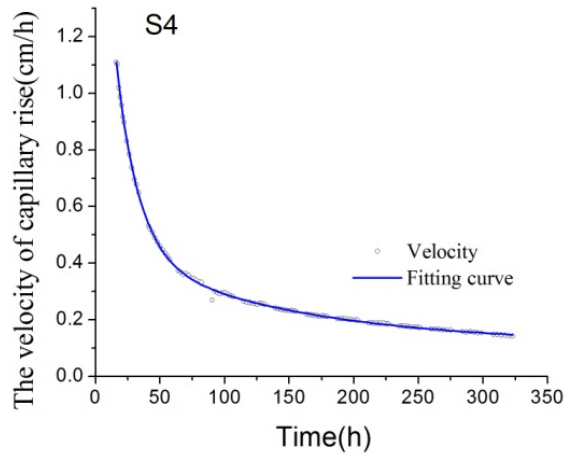

(d)

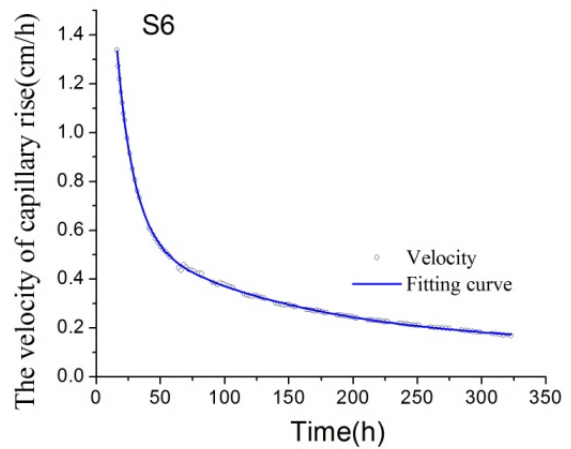

(f)

Figure 9. Cont. 


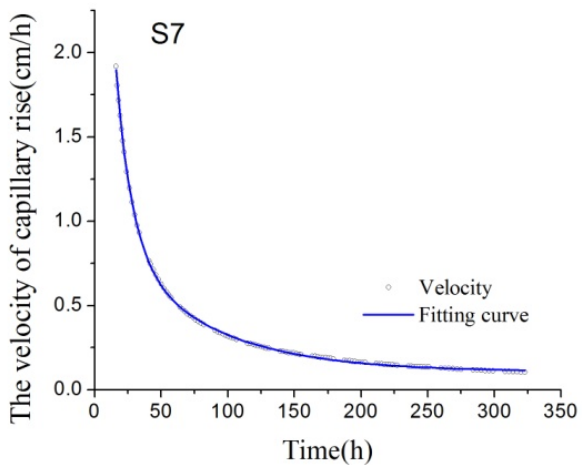

(g)

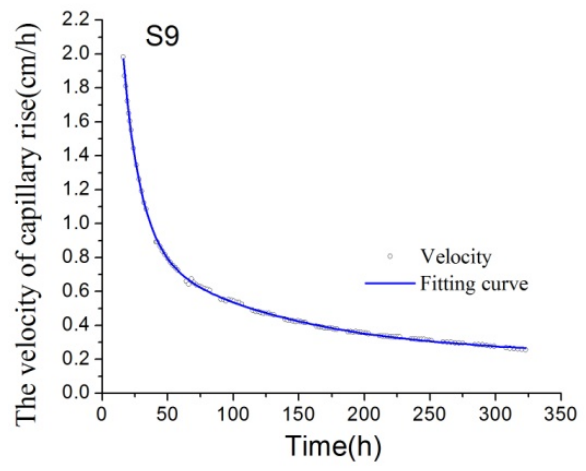

(i)

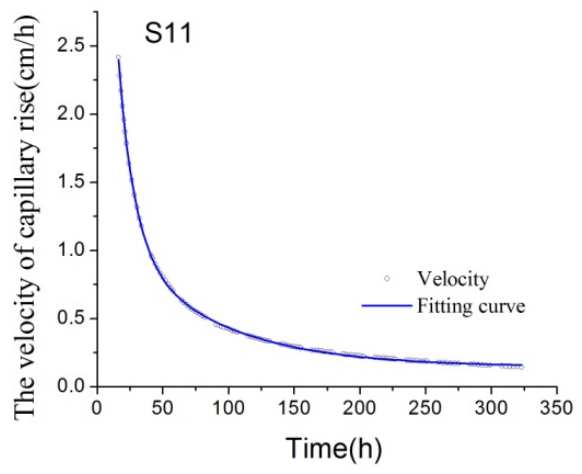

(k)

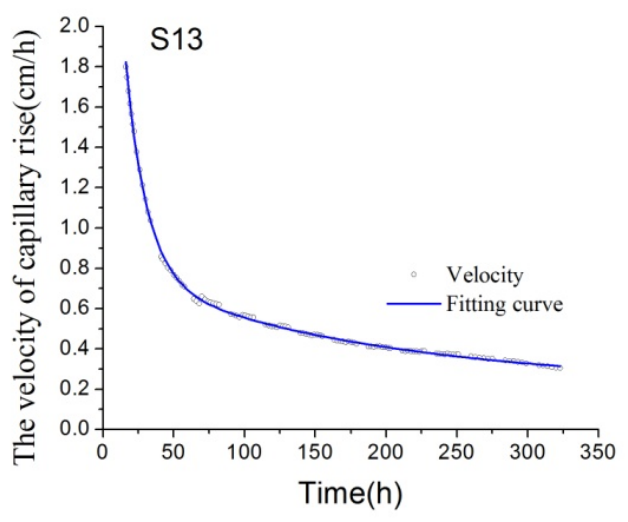

(m)

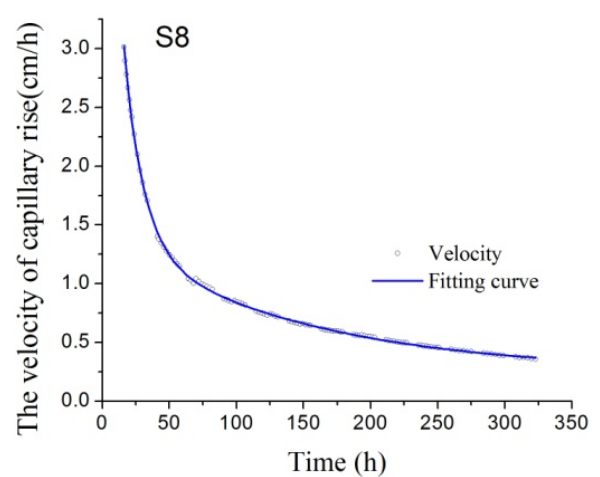

(h)

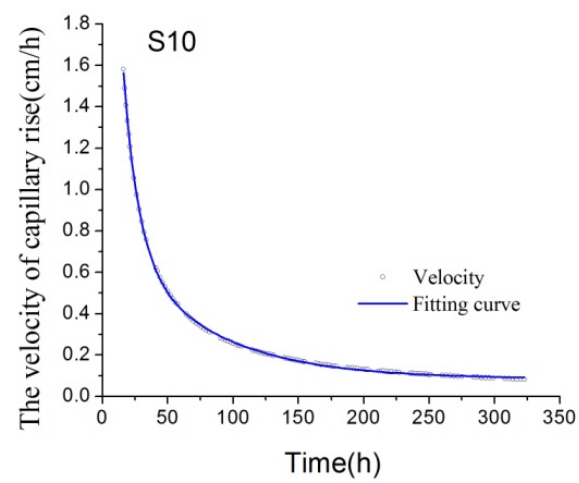

(j)

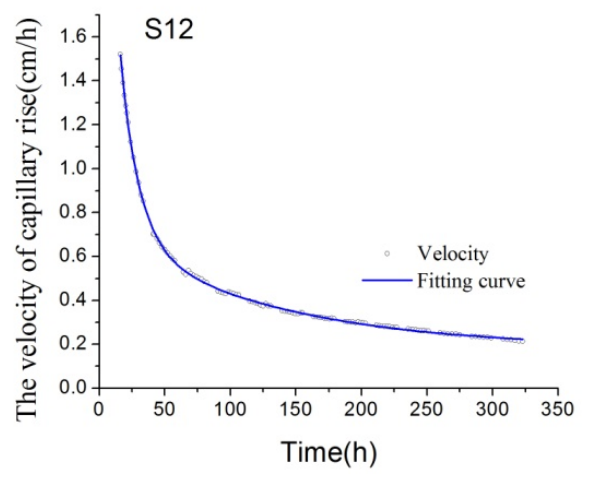

(I)

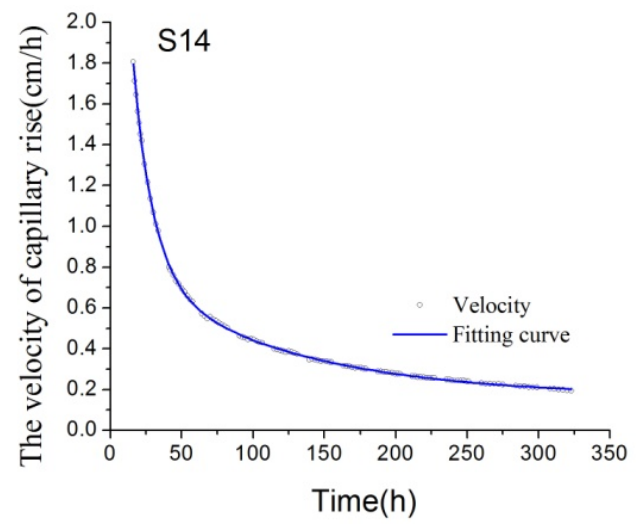

(n)

Figure 9. Cont. 


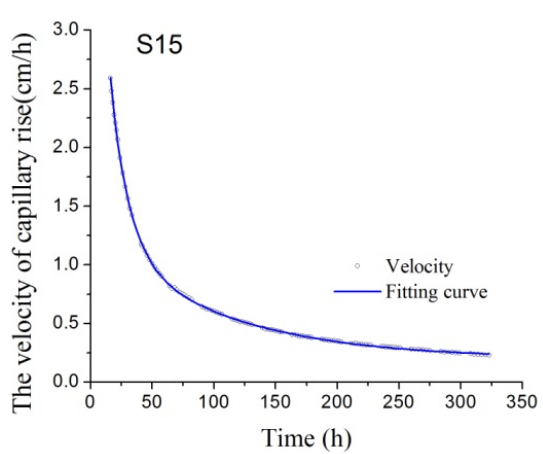

(o)

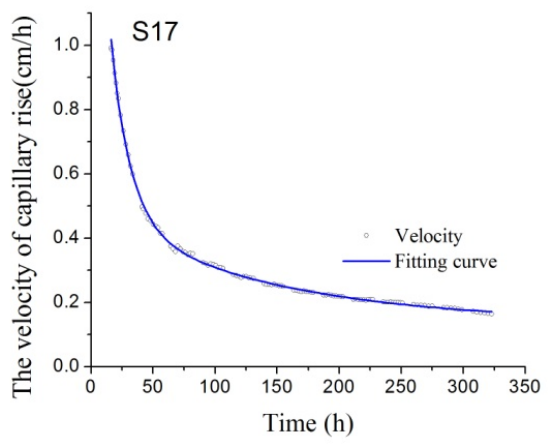

(q)

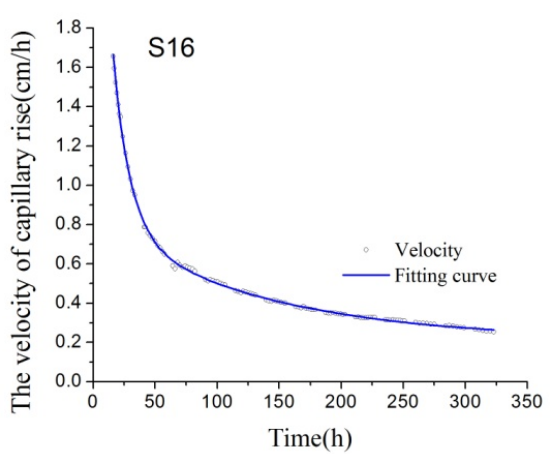

(p)

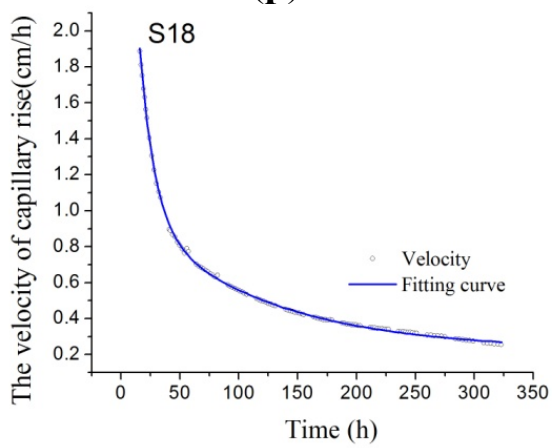

(r)

Figure 9. Velocity of capillary rise of 18 major soil types in the Sanjiang Plain, Northeast China. (a) S1; (b) S2; (c) S3; (d) S4; (e) S5; (f) S6; (g) S7; (h) S8; (i) S9; (j) S10; (k) S11; (l) S12; (m) S13; (n) S14; (o) S15; (p) S16; (q) S17; (r) S18.

In October 2013 we conducted field survey of rooting depth for several major plants and wood plants on the Sanjiang Plain. Intensive rooting depths of rice, corn, bean, Negundo artemisia, and green bristlegrass (Table 1) were measured through digging soil pits and the soil profiles.

In addition, we also used previously published data from two studies on wood plant below-ground growth in northeast China $[48,49]$ for determining wood plant (Lespedeza and Moraceae) rooting depths in the Sanjiang Plain (Table 1).

Table 1. Average rooting depths of major vegetation types on the Sanjiang Plain, Northeast China. The rooting depths were used to define their EISGD boundaries.

\begin{tabular}{cc}
\hline Main Plants & Rooting Depth/m \\
\hline Rice & 0.2 \\
Corn & 0.4 \\
Bean & 0.2 \\
Negundo artemisia & 0.1 \\
Green bristlegrass & 0.3 \\
Lespedeza & 1.8 \\
Moraceae & 2.2 \\
\hline
\end{tabular}

\subsection{EISGD Boundary Mapping and Regional Assessment}

Once the upper and lower EISGD boundaries were identified, we applied geospatial kriging technique to create spatial maps of EISGD for regional assessment. We used the mapping to assessment 
the condition of 2013 shallow groundwater of the Sanjiang Plain (Figure 10). Based on the mapping we defined three regions under different shallow groundwater conditions: (1) "excess region," a region whose shallow groundwater depth is above the upper boundary of EISGD (often near the surface); (2) "suitable region," a region whose shallow groundwater depth is within the upper boundary and the lower boundary of EISGD; and (3) "deficit region," a region where shallow groundwater depth is beyond the lower boundary of EISGD and sometimes far outside the range of EISGD.

We obtained the suitable regions by using the conditional function of "con(x)" in the Roster calculation of the ArcGIS software package (Eris Co., 2010, Redlands, CA, USA) using the following logic:

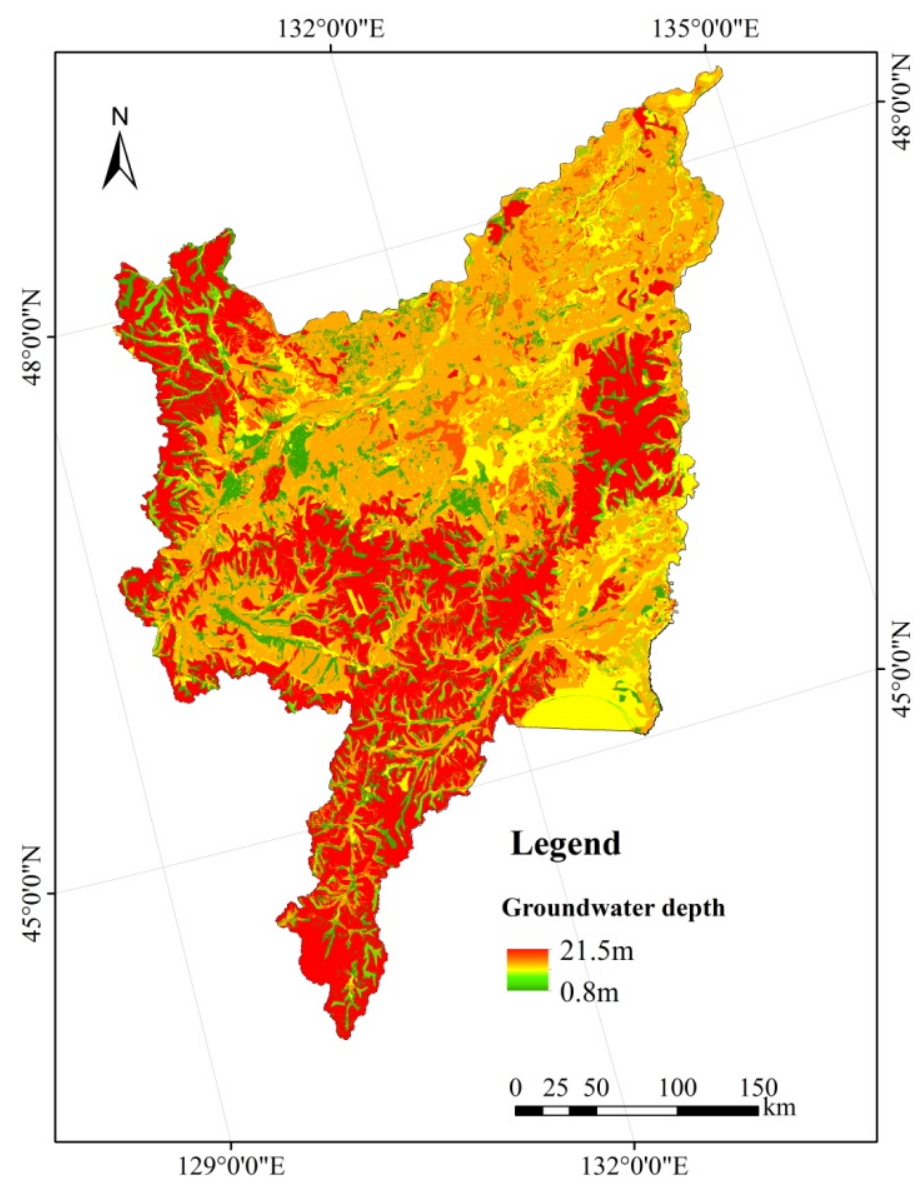

Figure 10. Groundwater depth for 2013 in the Sanjiang Plain, Northeast China.

If the actual groundwater depth of an area (b1) is less than its upper boundary of EISGD (b2), the area belongs to the excess region;

If the actual groundwater depth of an area (b1) is between its upper boundary of EISGD of an area (b2) and its lower boundary of EISGD (b3), the area belongs to the suitable region;

If the actual groundwater depth of an area (b1) is greater than its lower boundary of EISGD (b3), the area belongs to the deficit region.

\subsection{Allowable Withdrawal of EISGD-Based Shallow Groundwater}

Using the information on spatial distribution of EISGD and current shallow groundwater depth, we estimated allowable shallow groundwater withdrawal. The computation used the following equation: 


$$
\Delta Q=\mu \cdot A \cdot \frac{\Delta h}{\Delta t}
$$

where $\Delta Q$ is the changing groundwater quantity within a certain time interval; $\mu$ is the specific yield; $A$ is the region area; $\Delta h$ is the difference between the final groundwater depth and initial groundwater depth corresponding to the $\Delta t$; and $\Delta t$ is the unit, time.

\section{Results}

\subsection{Boundary of EISGD}

For the five major vegetation types in the Sanjiang Plain, we identified a lower EISGD boundary range between $2.0 \mathrm{~m}$ and $14.3 \mathrm{~m}$ (Table 2 and Figure 11) and an upper EISGD boundary range between $0.5 \mathrm{~m}$ and $2.8 \mathrm{~m}$ (Table 2, Table 3, and Figure 12).

Table 2. The lower boundary of ecologically ideal shallow groundwater depth (EISGD) of the Sanjiang Plain in Northeast China. An EISGD lower boundary represents the hypothetical extinction depth of a certain vegetation cover (for further explanation, see Section 3.1.2).

\begin{tabular}{|c|c|c|c|}
\hline City & Well ID & Lower of EISGD $/ \mathrm{m}$ & Mean $/ \mathbf{m}$ \\
\hline \multirow{9}{*}{ Fuyuan } & 10178180.00 & 10.5 & \multirow{9}{*}{12.1} \\
\hline & 10178080.00 & 6.2 & \\
\hline & 10500400.00 & 9.5 & \\
\hline & 10178060.00 & 10.6 & \\
\hline & 10178090.00 & 18.5 & \\
\hline & 10178110.00 & 22.4 & \\
\hline & 10178140.00 & 10.6 & \\
\hline & 10178100.00 & 8.1 & \\
\hline & 10178170.00 & 12.5 & \\
\hline \multirow{10}{*}{ Raohe } & 10561040.00 & 9.8 & \multirow{10}{*}{8.7} \\
\hline & 10561040.00 & 8.4 & \\
\hline & 10561110.00 & 7.6 & \\
\hline & 10561070.00 & 7.4 & \\
\hline & 10500330.00 & 8.3 & \\
\hline & 110561080.00 & 8.6 & \\
\hline & 10500020.00 & 8.2 & \\
\hline & 10561190.00 & 9.3 & \\
\hline & 10561220.00 & 9.6 & \\
\hline & 10561230.00 & 9.7 & \\
\hline \multirow{10}{*}{ Baoqing } & 10573040.00 & 2.9 & \multirow{10}{*}{2.3} \\
\hline & 10573140.00 & 1.7 & \\
\hline & 10573080.00 & 1.9 & \\
\hline & 10573060.00 & 1.9 & \\
\hline & 10573010.00 & 1.8 & \\
\hline & 10573050.00 & 2.0 & \\
\hline & 10573120.00 & 2.6 & \\
\hline & 10573110.00 & 2.3 & \\
\hline & 10573070.00 & 2.8 & \\
\hline & 10573200.00 & 2.9 & \\
\hline
\end{tabular}


Table 2. Cont.

\begin{tabular}{|c|c|c|c|}
\hline City & Well ID & Lower of EISGD $/ \mathrm{m}$ & Mean $/ \mathrm{m}$ \\
\hline \multirow{4}{*}{ Fujin } & 10577150.00 & 6.9 & \multirow{4}{*}{7.3} \\
\hline & 10577110.00 & 7.5 & \\
\hline & 10577190.00 & 7.6 & \\
\hline & 10700151.00 & 7.2 & \\
\hline \multirow{2}{*}{ Youyi } & 10575060.00 & 6.1 & \multirow{2}{*}{7.8} \\
\hline & 10575030.00 & 9.5 & \\
\hline \multirow{3}{*}{ Shuangyashan } & 11168020.00 & 4.8 & \multirow{3}{*}{3.5} \\
\hline & 11168040.00 & 3.6 & \\
\hline & 11168030.00 & 2.2 & \\
\hline \multirow{2}{*}{ Jixian } & 11100592.00 & 18.9 & \multirow{2}{*}{14.8} \\
\hline & 11169010.00 & 10.7 & \\
\hline \multirow{6}{*}{ Huachuan } & 10779050.00 & 9.3 & \multirow{6}{*}{7.1} \\
\hline & 10779030.00 & 4.9 & \\
\hline & 10779020.00 & 8.6 & \\
\hline & 10779070.00 & 5.2 & \\
\hline & 10779060.00 & 6.5 & \\
\hline & 10779040.00 & 7.8 & \\
\hline \multirow{8}{*}{ Suibin } & 10779531.00 & 7.0 & \multirow[b]{8}{*}{8.2} \\
\hline & 10100140.00 & 9.1 & \\
\hline & 10779550.00 & 7.0 & \\
\hline & 10779570.00 & 7.7 & \\
\hline & 10779580.00 & 8.5 & \\
\hline & 10779540.00 & 8.4 & \\
\hline & 10779520.00 & 9.0 & \\
\hline & 10779650.00 & 9.1 & \\
\hline \multirow{8}{*}{ Luobei } & 10471050.00 & 9.1 & \multirow{8}{*}{8.1} \\
\hline & 10471120.00 & 6.6 & \\
\hline & 10471030.00 & 7.2 & \\
\hline & 10471020.00 & 7.6 & \\
\hline & 10471130.00 & 7.4 & \\
\hline & 10471100.00 & 8.6 & \\
\hline & 10471080.00 & 9.2 & \\
\hline & 11100540.00 & 8.7 & \\
\hline \multirow{5}{*}{ Jiamusi } & 10778430.00 & 7.8 & \multirow{5}{*}{8.6} \\
\hline & 10700120.00 & 9.3 & \\
\hline & 10778470.00 & 8.2 & \\
\hline & 10778040.00 & 8.6 & \\
\hline & 10778030.00 & 9.2 & \\
\hline \multirow{8}{*}{ Tangyuan } & 11165030.00 & 8.5 & \multirow{8}{*}{7.7} \\
\hline & 11100520.00 & 6.6 & \\
\hline & 11100520.00 & 7.2 & \\
\hline & 11165060.00 & 7.6 & \\
\hline & 11165090.00 & 8.5 & \\
\hline & 11165120.00 & 6.9 & \\
\hline & 11165080.00 & 7.8 & \\
\hline & 11165160.00 & 8.2 & \\
\hline \multirow{2}{*}{ Tongjiang } & 10473100.00 & 7.8 & \multirow{2}{*}{6.3} \\
\hline & 10473120.00 & 4.8 & \\
\hline
\end{tabular}


Table 2. Cont.

\begin{tabular}{cccc}
\hline City & Well ID & Lower of EISGD/m & Mean $/ \mathbf{m}$ \\
\hline \multirow{6}{*}{ Huanan } & 11100370.00 & 8.6 & \\
& 11100350.00 & 5.5 & \\
& 11163050.00 & 4.4 & \\
& 11163070.00 & 3.5 & \\
& 11163080.00 & 3.9 & \\
& 11163090.00 & 4.3 & \\
& 11163110.00 & 5.4 & 7.0 \\
Boli & 11163100.00 & 5.5 & \\
\hline Qitaihe & 11162020.00 & 5.3 & \\
\hline & 11162040.00 & 8.9 & \\
\hline
\end{tabular}

$130^{\circ} 0^{\prime} 0 " \mathrm{E} \quad 132^{\circ} 0^{\prime} 0^{\prime \prime} \mathrm{E} \quad 134^{\circ} 0^{\prime} 0^{\prime \prime} \mathrm{E} \quad 136^{\circ} 0^{\prime} 0^{\prime \prime} \mathrm{E}$

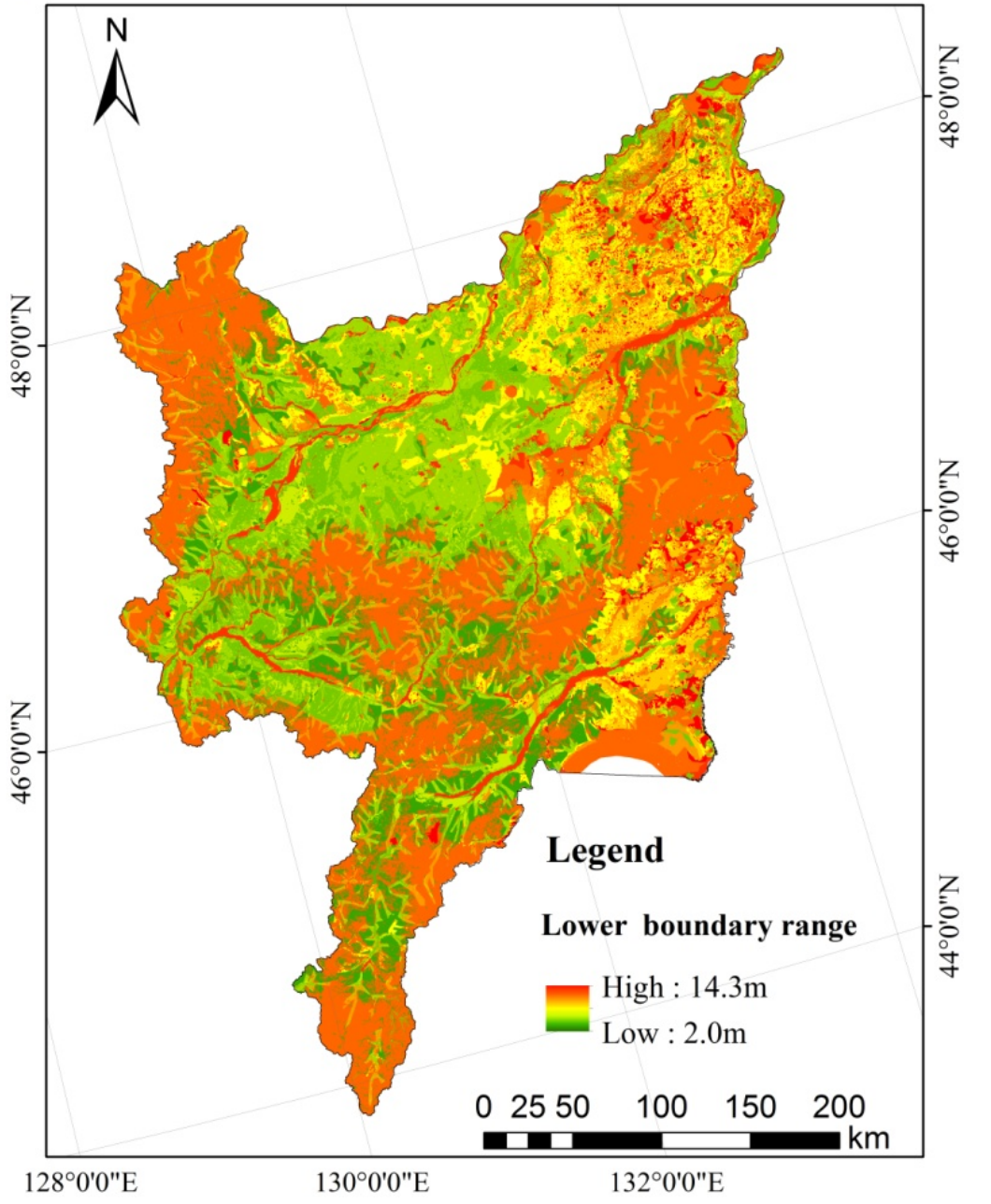

Figure 11. Spatial distribution of the lower boundary of ecologically ideal shallow groundwater depth (EISGD) in the Sanjiang Plain, northeast China. Five major vegetation types in the region were identified a lower EISGD boundary ranging from 2.0 to $14.3 \mathrm{~m}$. 
Table 3. Capillary rise heights of phreatic surface (CRHP) on the Sanjiang Plain, Northeast China, and the regressions used for their estimation.

\begin{tabular}{|c|c|c|c|c|}
\hline Sites & Functions & Fitting Curve & $\mathbf{R}^{2}$ & CRHP(m) \\
\hline \multirow{2}{*}{ S1 } & $h-t$ & $y=14.153 \ln (x)+13.978$ & 0.9051 & \multirow{2}{*}{1.8} \\
\hline & $v-\mathrm{t}$ & $\mathrm{y}=27.082 x^{-0.764}$ & 0.9825 & \\
\hline \multirow{2}{*}{$\mathrm{S} 2$} & h-t & $y=1.42 \ln (x)+11.898$ & 0.9744 & \multirow{2}{*}{0.5} \\
\hline & $v-\mathrm{t}$ & $y=12.976 x^{-0.924}$ & 0.9995 & \\
\hline \multirow{2}{*}{$\mathrm{S} 3$} & $h-t$ & $y=5.0915 \ln (x)+7.6914$ & 0.8948 & \multirow{2}{*}{0.6} \\
\hline & $v-\mathrm{t}$ & $y=7.3382 x^{-0.696}$ & 0.9930 & \\
\hline \multirow{2}{*}{$\mathrm{S} 4$} & $h-t$ & $y=5.7629 \ln (x)+5.8171$ & 0.8591 & \multirow{2}{*}{0.7} \\
\hline & $v-\mathrm{t}$ & $y=6.2311 x^{-0.655}$ & 0.9921 & \\
\hline \multirow{2}{*}{ S5 } & $h-t$ & $y=10.105 \ln (x)+6.7279$ & 0.8477 & \multirow{2}{*}{1.2} \\
\hline & $v-t$ & $\mathrm{y}=8.5344 x^{-0.617}$ & 0.9913 & \\
\hline \multirow{2}{*}{ S6 } & $h-t$ & $y=7.3208 \ln (x)+6.3176$ & 0.8893 & \multirow{2}{*}{0.9} \\
\hline & $v-t$ & $y=7.1143 x^{-0.64}$ & 0.9941 & \\
\hline \multirow{2}{*}{ S7 } & h-t & $y=1.9782 \ln (x)+23.331$ & 0.8062 & \multirow{2}{*}{1.1} \\
\hline & $v-t$ & $y=27.691 x^{-0.967}$ & 0.9999 & \\
\hline \multirow{2}{*}{ S8 } & h-t & $y=16.815 \ln (x)+10.936$ & 0.9167 & \multirow{2}{*}{0.7} \\
\hline & $v-\mathrm{t}$ & $y=18.127 x^{-0.668}$ & 0.9956 & \\
\hline \multirow{2}{*}{ S9 } & h-t & $y=11.108 \ln (x)+7.3621$ & 0.8959 & \multirow{2}{*}{1.4} \\
\hline & $v-\mathrm{t}$ & $y=11.794 \ln (x)+5.068$ & 0.9003 & \\
\hline \multirow{2}{*}{$\mathrm{S} 10$} & h-t & $y=10.085 x^{-0.63}$ & 0.9967 & \multirow{2}{*}{1.1} \\
\hline & $v-\mathrm{t}$ & $y=10.372 x^{-0.639}$ & 0.9943 & \\
\hline \multirow{2}{*}{ S11 } & h-t & $y=1.3546 \ln (x)+19.87$ & 0.9410 & \multirow{2}{*}{0.5} \\
\hline & $v-\mathrm{t}$ & $y=23.749 x^{-0.981}$ & 0.9999 & \\
\hline \multirow{2}{*}{ S12 } & h-t & $y=3.4666 \ln (x)+27.556$ & 0.9055 & \multirow{2}{*}{0.5} \\
\hline & $v-\mathrm{t}$ & $y=30.547 x^{-0.926}$ & 0.9997 & \\
\hline \multirow{2}{*}{ S13 } & h-t & $y=9.5032 \ln (x)+4.1629$ & 0.8833 & \multirow{2}{*}{1.2} \\
\hline & $v-\mathrm{t}$ & $y=7.3138 x^{-0.609}$ & 0.9928 & \\
\hline \multirow{2}{*}{ S14 } & h-t & $y=13.531 \ln (x)+2.4436$ & 0.8414 & \multirow{2}{*}{1.4} \\
\hline & $v-\mathrm{t}$ & $y=6.9448 x^{-0.539}$ & 0.9829 & \\
\hline S1 & h-t & $y=8.1193 \ln (x)+9.6878$ & 0.9263 & 06 \\
\hline S15 & $v-\mathrm{t}$ & $y=11.793 x^{-0.709}$ & 0.9966 & 0.6 \\
\hline S16 & h-t & $y=10.402 \ln (x)+12.814$ & 0.9696 & 12 \\
\hline 510 & $v-t$ & $y=23.37 x^{-0.795}$ & 0.9994 & 1.2 \\
\hline $\mathrm{S} 17$ & h-t & $y=11.271 \ln (x)+4.0682$ & 0.8676 & 05 \\
\hline $\mathrm{S11}$ & $v-\mathrm{t}$ & $y=7.3882 x^{-0.58}$ & 0.9922 & 0.5 \\
\hline S18 & $h-t$ & $y=7.2199 \ln (x)+1.981$ & 0.8466 & 00 \\
\hline 518 & $v-\mathrm{t}$ & $y=4.384 x^{-0.568}$ & 0.9902 & 0.9 \\
\hline
\end{tabular}




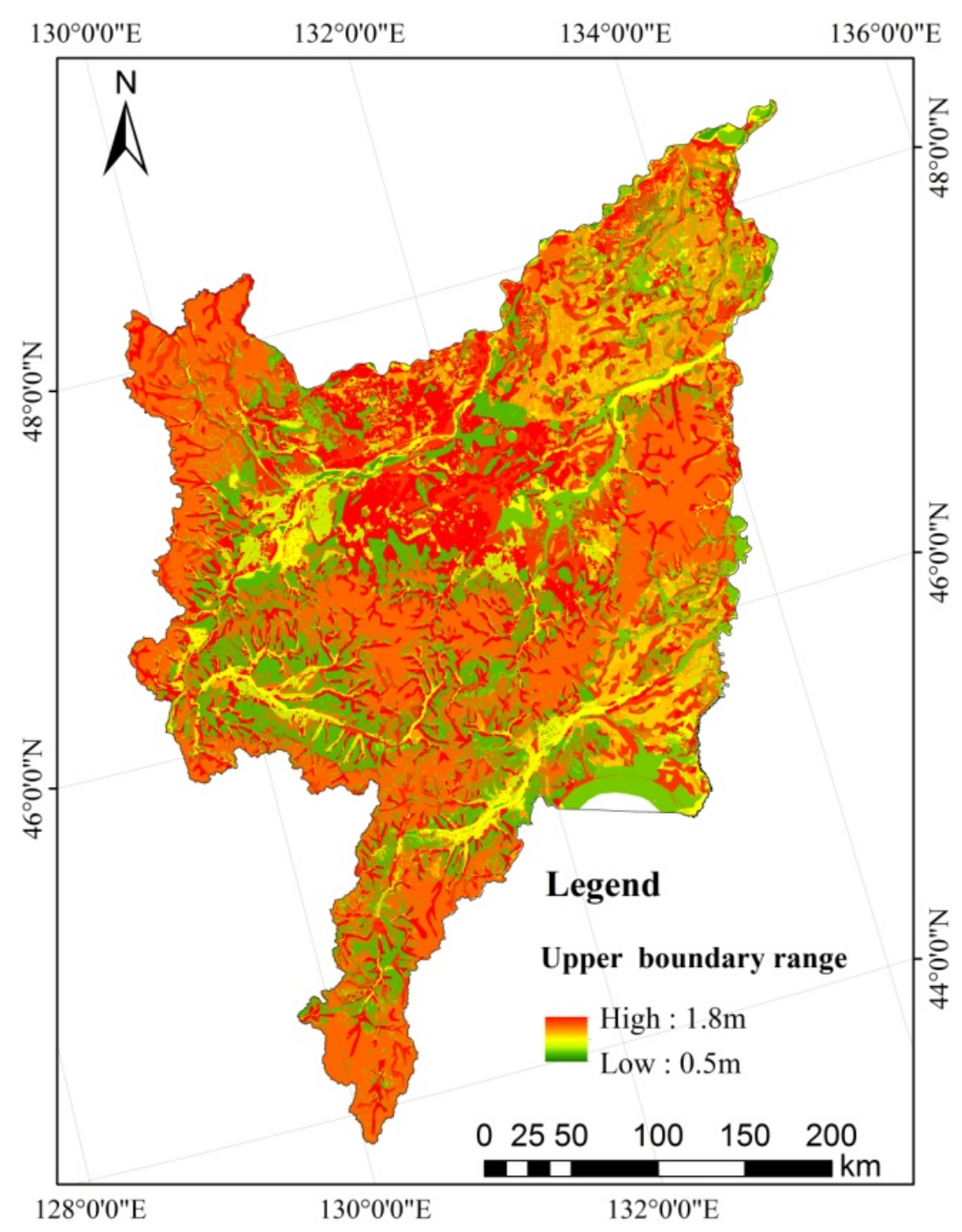

Figure 12. Spatial distribution of the upper boundary of ecologically ideal shallow groundwater depth (EISGD) in the Sanjiang Plain, northeast China. Five vegetation types in the region were used for defining an upper EISGD boundary ranging from 0.5 and $2.8 \mathrm{~m}$.

The rice paddies showed a range between 1.1 and $12.2 \mathrm{~m}$, with a mean value of $6.7 \mathrm{~m}$. The meadows had a wider range of EISGD from 0.8 to $13.9 \mathrm{~m}$, with an average of $7.3 \mathrm{~m}$. For the woodland areas, we identified an EISGD range between 2.4 and $14.3 \mathrm{~m}$, with a mean of $8.3 \mathrm{~m}$. For the crop farmland, we found an EISGD range between 0.8 and $9.3 \mathrm{~m}$, with a mean of $5.1 \mathrm{~m}$. For the wetlands, we identified an EISGD range between 0.5 and $13.4 \mathrm{~m}$, with an average of $6.9 \mathrm{~m}$ (Figure 13). Spatially, the deepest and shallowest lower boundaries of EISGD occurred in the northeast and southeast areas of the Sanjiang Plain, respectively (Table 2 and Figure 11). The deepest and shallowest upper boundaries of EISGD were located in the north and southeast of the Sanjiang Plain, respectively (Table 3, Table 4 and Figure 12). As for the entire Sanjiang Plain, the largest $(13.9 \mathrm{~m})$ and smallest $(6.4 \mathrm{~m})$ range of EISGD mainly occurred in the northeast and central Sanjiang Plain, respectively (Figure 13), indicating a potentially higher pumping capacity of the area when compared with other areas on the Sanjiang Plain. 


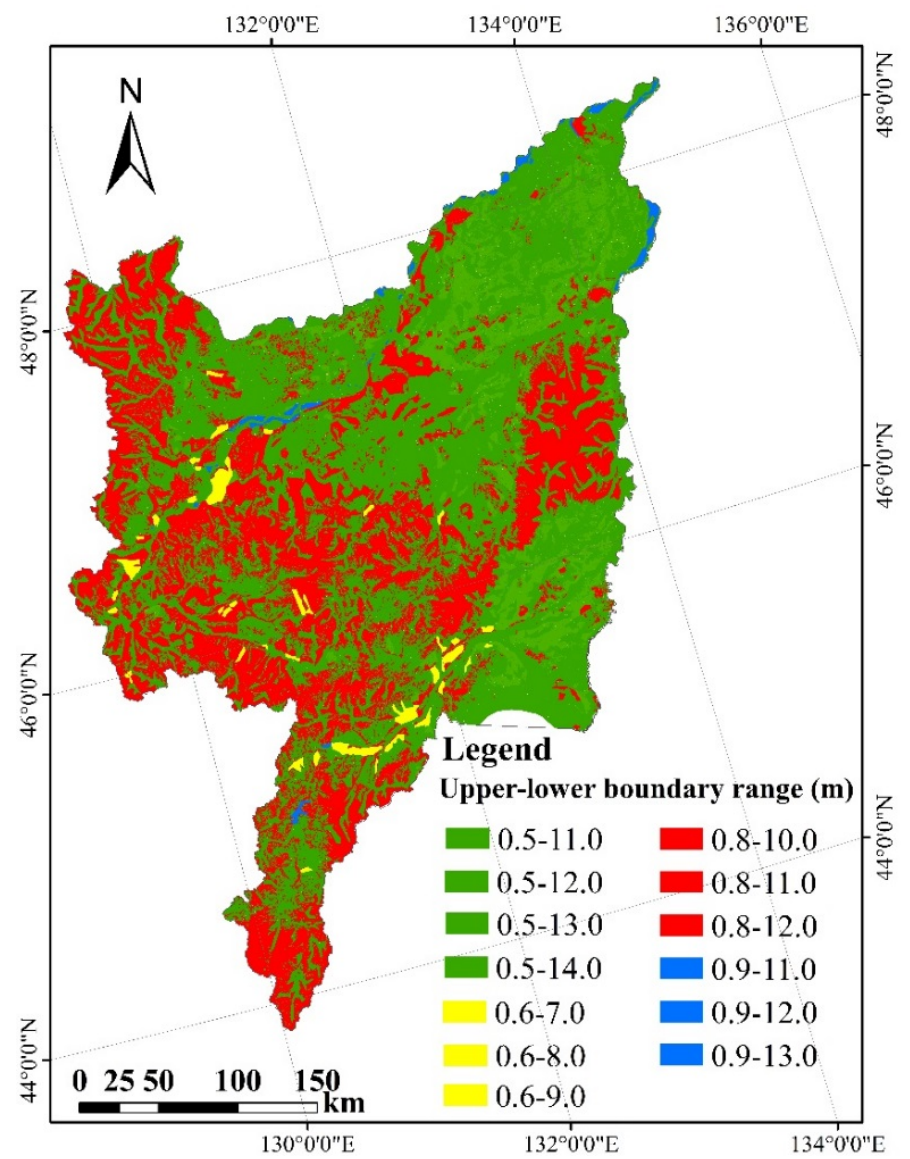

Figure 13. Ranges of ecologically ideal shallow groundwater depth (EISGD) in the Sanjiang Plain, northeast China. Average EISGD was estimated for five major vegetation types including rice paddies $(6.7 \mathrm{~m})$, meadows $(7.3 \mathrm{~m})$, woodland areas $(8.3 \mathrm{~m})$, crop farmland $(5.1 \mathrm{~m})$, and wetlands $(6.9 \mathrm{~m})$.

Table 4. The upper boundary of ecologically ideal shallow groundwater depth (EISGD) of the Sanjiang Plain in Northeast China.

\begin{tabular}{cccccc}
\hline Site & Land-Use Type & CRHP $(\mathbf{m})$ & Plant Rooting Depth $(\mathbf{m})$ & The Lower of EISGD (m) & Mean (m) \\
\hline S1 & corn & 1.6 & 0.4 & 2.0 & \\
S3 & corn & 0.6 & 0.4 & 1.0 & 1.8 \\
S9 & corn & 1.4 & 0.4 & 1.6 & \\
S16 & corn & 1.2 & 0.4 & 0.5 & \\
\hline S2 & wetland & 0.5 & - & 1.2 & \\
S5 & wetland & 1.2 & - & 0.9 & 0.8 \\
S6 & wetland & 0.9 & - & 0.5 & \\
S11 & wetland & 0.5 & - & 0.9 & 1.2 \\
S18 & wetland & 0.9 & - & 0.8 & \\
\hline S7 & meadow & 0.4 & 0.4 & 1.8 & 1.3 \\
S10 & meadow & 1.4 & 0.4 & 1.0 & \\
S12 & meadow & 0.6 & 0.4 & 0.9 & 1.4 \\
\hline S4 & rice & 0.7 & 0.2 & 1.6 & 2.6 \\
S13 & rice & 1.2 & 0.2 & 2.8 & \\
S14 & rice & 1.4 & 0.2 & 2.6 & \\
\hline S8 & woodland & 0.8 & 2 & 2.4 & \\
S15 & woodland & 0.6 & 2 & & \\
S17 & woodland & 0.4 & 2 & & \\
\hline
\end{tabular}




\subsection{Suitable Regions Distribution and Allowable Withdrawal Shallow Groundwater (AWG)}

Of the whole Sanjiang Plain, there were three suitable regions (Figure 14). The excess region had an area of $1.22 \times 10^{10} \mathrm{~m}^{2}$, which accounts for $11.2 \%$ of the whole area of the Sanjiang Plain, and the water beyond the range of EISGD was $7.32 \times 10^{8} \mathrm{~m}^{3}$; the suitable region had an area of $7.14 \times 10^{10} \mathrm{~m}^{2}$, which has a percentage of $65.5 \%$, and the withdrawal shallow groundwater was $47.12 \times 10^{8} \mathrm{~m}^{3}$. For the deficit region, where a large amount of groundwater was pumped in the past few years, the shallow groundwater depth had an excess in the lower range of EISGD: it lacked $9.14 \times 10^{8} \mathrm{~m}^{3}$ water, with an area of $2.54 \times 10^{10} \mathrm{~m}^{2}, 23.3 \%$ of the whole area of the Sanjiang Plain. Finally, the whole allowable withdrawal shallow groundwater was $45.30 \times 10^{8} \mathrm{~m}^{3}$ (Figure 14). This indicates that any pumping plan or water management strategy in the Sanjiang Plain should not be higher than $45.30 \times 10^{8} \mathrm{~m}^{3}$, otherwise a continuous declining of shallow groundwater in the Sanjiang Plain can lead to unsustainable irrigation and the degradation of local wetlands.

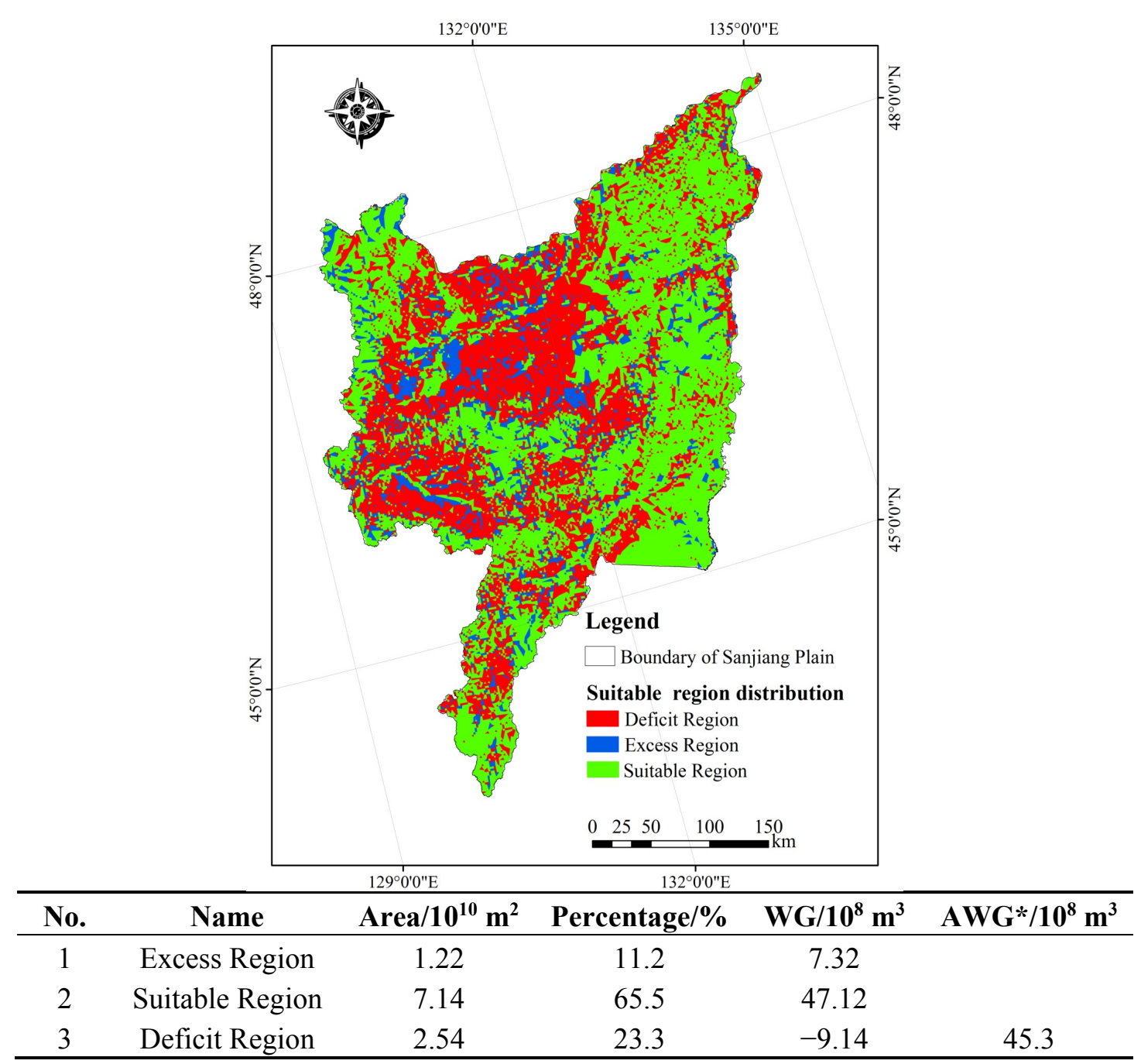

Figure 14. Distribution of areas whose shallow groundwater depth is within (i.e., suitable) or outside of (i.e., deficit and excess) EISGD and the withdrawal shallow groundwater (WG) for different regions of the Sanjiang Plain, northeast China. * AWG = allowable withdrawal shallow groundwater for total Sanjiang Plain-Stands for water shortage reaching the range of EISGD. 


\section{Discussion}

The principal aim of this study was to develop an ecologically-based concept for accessing shallow groundwater conditions. Based on vegetation types, soil types, and local evaporation characteristics of shallow groundwater, we proposed a lower and an upper boundary of ecologically ideal shallow groundwater depth and applied the concept to the Sanjiang Plain in northeast China. Currently, the total allowable withdrawal of shallow groundwater (AWG), in the Sanjiang Plain, estimated based on the EISGD concept, is about $45.30 \times 10^{8} \mathrm{~m}^{3}$. Yang et al. [31] calculated $51.45 \times 10^{8} \mathrm{~m}^{3}$ groundwater resources for this region using a water balance method. This estimation is about $10 \%$ higher than our estimation because we take surface vegetation types, soils types, and their spatial distributions into account, indicating the plausibility of the EISGD application for assessment of regional shallow groundwater conditions.

In addition, we found the different EISGD values for different surface vegetation (Figures 9 and 10), so when we design a water resources management plan, it can help us to protect the surface vegetation without degradation or shift. There are five land-use types in the Sanjiang Plain (Table 4), of which rice is the main plant. When water is withdrawn from shallow groundwater, the continuous decline of shallow groundwater depth can exert detrimental effects on the surface vegetation community, in particularly for plants with a shallow rooting depth (e.g., meadow and corn). Without considering the spatial distribution of surface vegetation and types, we would fail to offer effective help in regional ecological protecting and water resources management. Sun et al. [19] proposed a range of EGWTs (ecological groundwater tables) (from 2 to $17 \mathrm{~m}$ ) for the Sanjiang Plain. In our study, we found a wider lower boundary of EISGD (between 2.0 and $14.3 \mathrm{~m}$ ) and upper boundary of EISGD range between 0.5 and $1.8 \mathrm{~m}$ for the Sanjiang Plain. Those differences may have resulted from the different methods used. Sun et al. [19] used field surveys but did not consider surface vegetation. This method depends on empirical assumption, and always has a relatively high error. We applied the rooting depth of a certain vegetation type, capillary rise of water in the soil, and evaporation of the shallow groundwater to assess the range of EISGD; because it is based on the actual physical process, it has higher accuracy.

Our study found that $65.5 \%$ of the entire Sanjiang Plain was within their EISGD ranges. Another $23.3 \%$ of the Sanjiang Plain has shallow groundwater outside their EISGD ranges, and these areas are mostly located in the north and northeast parts of the Sanjiang Plain. These deficit areas are almost solely large farmland, where shallow groundwater has been pumped extensively in the past two decades, leading to a rapid drop in the groundwater depth [26]. The deficit water quantity in the unsuitable region is $9.14 \times 10^{8} \mathrm{~m}^{3}$, which can cause surface vegetation degradation and unsustainable irrigation. The remaining $11.2 \%$ of the Sanjiang Plain was kept at the lower shallow groundwater depth whose depth should decrease to the range of EISGD. These areas have a total deficit of $7.32 \times 10^{8} \mathrm{~m}^{3}$, the highest deficit rate of $0.5 \mathrm{~m} / \mathrm{year}$ in the Sanjiang Plain. This indicates that those areas should decrease their groundwater pumping quantity.

Many factors can affect the EISGD (e.g., soil factors, vegetation species and density, and topography). Different soils have different physical properties, affecting the capillary rise of shallow groundwater [50-52]. The results of capillary rise height from our laboratory measurement showed that evaporation of groundwater was nearly zero unless the surface vegetation roots reached the water table. The Sanjiang Plain is large $\left(10.9 \times 10^{4} \mathrm{~km}^{2}\right)$ and our limited project funding prohibited intensive 
field soil coring for collecting undisturbed soil columns. When collecting soil samples in the field, we measured the soil moisture content, dry density, and wet density at each sampling depth. When the samples were filled into the vertical tubes, we filled it under the original density and order and tried to keep the original soil field condition as much as possible. In addition, the different soils and land vegetation can also affect the extinction depth (i.e., the lower boundary): fine-textured soils have deeper extinction depth than coarse-textured soils under the same land vegetation. Therefore, the representative and distribution of soil samplings would affect the average extinction depth. Meanwhile, extinction depth increased with the increasing of land vegetation rooting depth [53]. Thus the universality and accuracy of vegetation rooting depth value would affect the stability and uniqueness of extinction depth. Therefore, the method to define the upper and lower boundary of EISGD model is sensitive to the representativeness of soil and vegetation samplings. Those factors would introduce uncertainty as to the application the EISGD model. Selection of highly representative soil and vegetation types could improve the adaptability of this method, especially for large-scale regions.

The EISGD concept that we developed in this study uses a simple way of estimating the evaporation of shallow groundwater. The accuracy of this approach needs to be tested in laboratory and field experiments under different climatic conditions. This can especially improve the identification of a realistic lower boundary.

The EISGD approach can be very useful for evaluation and management of large-scale regional shallow groundwater resources. For regions that have sufficient information on shallow groundwater, the approach provides a comparative assessment of actual shallow groundwater depths with EISGD-based shallow groundwater depths, helping evaluate current groundwater conditions. For regions that have no or insufficient information on shallow groundwater, the approach can provide useful insights, helping develop sustainable shallow groundwater management. Because EISGD considers the impact of shallow groundwater on surface vegetation community, application of the approach can help develop management plans and strategies for regional ecological protection and restoration. Many farming areas on floodplains around the world have used groundwater for irrigation extensively, e.g., the High Plain (Ogallala Aquifer) in the USA. These areas are experiencing similar environmental problems including cone of depression and surface ecology degradation. Those areas can utilize the EISGD model to estimate regional groundwater deficit conditions and control groundwater pumpage. In the future, the approach can be improved with more accurate field data (e.g., groundwater depth, rooting depth, and field capillary rise measurements).

\section{Conclusions}

This study developed a conceptual model of ecologically ideal shallow groundwater depth (EISGD). The model identifies an upper boundary and a lower boundary of shallow groundwater using soil capillary rise, vegetation rooting depth, and evaporation of shallow groundwater. We applied the model to a large-scale region in northeast China with different vegetation types, soil types, and evaporative characteristics to determine an upper and a lower boundary of EISGD. We then analyzed the spatial distribution of the EISGD ranges and estimated allowable withdrawal of shallow groundwater (i.e., without degrading the present vegetation ecosystem). The results showed the plausibility and usefulness of the EISGD concept. In addition to the methodological development, the study yielded 
insights into the current shallow groundwater conditions in one of China's largest grain production bases. Currently, $23.3 \%$ of the land in the Sanjiang Plain has already reached beyond the EISGD; if the present groundwater pumpage continues, there may be severe consequences for surface vegetation in these areas. This study demonstrated that application of the EISGD concept can be helpful for assessing the conditions of present shallow groundwater with respect to surface vegetation, as well as in determining sustainably allowable groundwater withdrawal at the landscape scale.

\section{Acknowledgments}

This research was supported by the Key Research Program of the Chinese Academy of Sciences (KSZD-EW-Z-021), the CAS/SAFEA International Partnership Program for Creative Research Teams, the National Natural Science Foundation of China (Grant No. 41371108), and the Scientific Research Project of the Public Welfare Industry of the Ministry of Water Resources, China (No. 201401014). Meteorological data were provided by the Chinese Meteorological Data Sharing Service System.

\section{Author Contributions}

All authors contributed to the design and development of this manuscript. Xihua Wang carried out the data analysis and prepared the first draft of the manuscript; Guangxin Zhang is the advisor of Xihua Wang and contributed many ideas to the study; Yi Jun Xu provided many important advices on the concept of method and structuring of the manuscript, as well as edited the manuscript prior to submission and during revisions; Xiangjun Shan provided the English language modifying and funding. All authors read and approved the final manuscript.

\section{Conflicts of Interest}

The authors declare no conflict of interest.

\section{References}

1. Quinn, P.; Beven, K.; Culf, A. The introduction of macroscale hydrological complexity into land surface-atmosphere transfer models and the effect on planetary boundary layer development. J. Hydrol. 1995, 166, 421-444.

2. York, J.P.; Person, M.; Gutowski, W.J.; Winter, T.C. Putting aquifers into atmospheric simulation models: An example from the Mill Creek Watershed, Northeastern Kansas. Adv. Water Resour. 2002, 25, 221-238.

3. Yeh, P.J.F.; Eltahir, E.A. Representation of water table dynamics in a land surface scheme. Part I: Model development. J. Clim. 2005, 18, 38-56.

4. Doble, R.; Simmons, C.; Jolly, I.; Walker, G. Spatial relationships between vegetation cover and irrigation-induced groundwater discharge on a semi-arid floodplain, Australia. J. Hydrol. 2006, 329, 75-97.

5. Kollet, S.J.; Maxwell, R.M. Capturing the influence of groundwater dynamics on land surface processes using an integrated, distributed watershed model. Water Resour. Res. 2008, 44, doi:10.1029/2007WR006004. 
6. Zhu, J.; Yu, J.; Wang, P,; Yu, Q.; Eamus, D. Variability in groundwater depth and composition and their impacts on vegetation succession in the lower Heihe River Basin, North-western China. Mar. Freshw. Res. 2013, 65, 206-217.

7. Kelliher, F.M.; Kirkham, M.B.; Tauer, C.G. Stomatal resistance, transpiration, and growth of drought-stressed eastern cottonwood. Can. J. For. Res. 1980, 10, 447-451.

8. Brothers, T.S. Historical vegetation change in the Owens River riparian woodland. Calif. Riparian Syst. 1984, 15, 75-84.

9. Kranjcec, J.; Mahoney, J.M.; Rood, S.B. The responses of three riparian cottonwood species to water table decline. For. Ecol. Manag. 1998, 110, 77-87.

10. Xu, Y.J.; Burger, J.A.; Aust, W.M. Responses of surface hydrology and early loblolly pine growth to soil disturbance and site preparation in a lower coastal plain wetland. N. Z. J. For. Sci. 2000, 30, 250-265.

11. Horton, J.L.; Clark, J.L. Water table decline alters growth and survival of Salix gooddingii and Tamarix chinensis seedlings. For. Ecol. Manag. 2001, 140, 239-247.

12. Naumburg, E.; Mata-Gonzalez, R.; Hunter, R.G.; Mclendon, T.; Martin, D.W. Phreatophytic vegetation and groundwater fluctuations: A review of current research and application of ecosystem response modeling with an emphasis on Great Basin vegetation. Environ. Manag. 2005, 35, 726-740.

13. Fan, Y.; Li, H.; Miguez-Macho, G. Global patterns of groundwater table depth. Science 2013, 339, 940-943.

14. Lowry, C.S.; Loheide, S.P.; Moore, C.E.; Lundquist, J.D. Groundwater controls on vegetation composition and patterning in mountain meadows. Water Resour. Res. 2011, 47, doi:10.1029/2010WR010086.

15. Satchithanantham, S.; Krahn, V.; Sri, R.R.; Sager, S. Shallow groundwater uptake and irrigation water redistribution within the potato root zone. Agric. Water Manag. 2014, 132, 101-110.

16. Schilling, O.S.; Doherty, J.; Kinzelbach, W.; Wang, H.; Yang, P.N.; Brunner, P. Using tree ring data as a proxy for transpiration to reduce predictive uncertainty of a model simulating groundwater-surface water-vegetation interactions. J. Hydrol. 2014, 519, 2258-2271.

17. Zhang, C.C.; Shao, J.L.; Li, C.J.; Cui, Y.L. A study on the ecological groundwater table in the North China Plain. J. Jilin Univ. (Earth Sci. Ed.) 2003, 33, 323-326. (In Chinese)

18. Zhang, X.; Gai, M. Ecological level of groundwater in the Haihe River valley. J. Geol. Hazards Environ. Preserv. 2005, 16, 87-88. (In Chinese)

19. Sun, X.G.; Ai, X.Y;; Zhang, L.C. The preliminary research on groundwater ecological water table in Sanjiang Plain. Heilongjiang Sci. Technol. Water Conserv. 2012, 40, 166-168. (In Chinese)

20. Brunner, P.; Li, H.T.; Kinzelbach, W.; Li, W.P. Generating soil electrical conductivity maps at regional level by integrating measurements on the ground and remote sensing data. Int. J. Remote Sens. 2007, 28, 3341-3361.

21. Brunner, P.; Li, H.T.; Kinzelbach, W.; Li, W.P.; Dong, X.G. Extracting phreatic evaporation from remotely sensed maps of evapotranspiration. Water Resour. Res. 2008, 44, doi:10.1029/ 2007WR006063. 
22. Sun, C.Z.; Gao, Y.; Zhu, Z.R. Estimation of ecological water demands based on ecological water table limitations in the lower reaches of the Liaohe River Plain, China. Acta Ecol. Sinica 2013, 33, 1513-1523. (In Chinese)

23. Sun, C.Z. Research on the ecological and sustainable groundwater table regulation in the lower Liaohe River plain. J. Jilin Univ. (Earth Sci. Ed.) 2007, 37, 249-254. (In Chinese)

24. Rong, L.S.; Shu, L.C.; Wang, M.M.; Deng, Z.B. Study on estimation method of ecological water level of reasonable groundwater-case study on lower reaches of the Tarim River. Ground Water 2009, 31, 12-16. (In Chinese)

25. Xin, X.J.; Xiang, G.S. Study on Reasonable Groundwater Exploitation Based on the Ecological Water Level in Zhangye Basin. Yellow River 2013, 8, 43-48. (In Chinese)

26. Zhao, Q.; Han, Y.M. Analysis of stimulated recharge of groundwater on the Jiansanjiang Farming Bureau, Sanjiang Plain. J. Heilongjiang Hydraul. Eng. Coll. 2008, 3, 1-4. (In Chinese)

27. Crosbie, R.S.; Scanlon, B.R.; Mpelasoka, F.S.; Reedy, R.C.; Gates, J.B.; Zhang, L. Potential climate change effects on groundwater recharge in the High Plains Aquifer, USA. Water Resour. Res. 2013, 49, 3936-3951.

28. Zeng, R.; Cai, X. Analyzing streamflow changes: Irrigation-enhanced interaction between aquifer and streamflow in the Republican River Basin. Hydrol. Earth Syst. Sci. Discuss. 2014, 10, 7783-7807.

29. Herrea-Pantoja, M.; Hiscock, K.M.; Boar, R.R. The potential impact of climate change on groundwater-fed wetlands in Eastern England. Ecohydrology 2012, 5, 401-413.

30. Wang, C.Y.; Wu, Z.J.; Shi, Y.L.;Wang, R.Y. The resource of saline soil in the Northeast China. Chin. J. Soil Sci. 2004, 35, 643-646. (In Chinese)

31. Yang, X.; Yang, W.; Zhang, F.; Chu, Y.; Wang, Y. Investigation and assessment of groundwater resources potential and eco-environment geology in Sanjiang Plain. In China Geology Survey; Geological Publishing House: Beijing, China, 2010. (In Chinese)

32. Pan, X.F.; Yan, B.X. Effects of land use and changes in cover on the transformation and transportation of iron: A case study of the Sanjiang Plain, Northeast China. Sci. China Earth Sci. 2011, 54, 686-693.

33. Wang, X.; Yan, B.X. The Spatial Variation and Factors Controlling the Concentration of Total Dissolved Iron in Rivers, Sanjiang Plain Clean. Soil Air Water 2012, 40, 712-717.

34. Cao, Y.J.; Tang, C.Y.; Song, X.F.; Liu, C.M.; Zhang, Y.H. Characteristics of nitrate in major rivers and aquifers of the Sanjiang Plain, China. J. Environ. Monit. 2012, 14, doi:10.1039/C2EM30032J.

35. Song, K.; Liu, D.; Wang, Z.; Zhang, B.; Jin, C.; Li, F.; Liu, H. Land use change in Sanjiang Plain and its driving forces analysis since 1954. J. Geogr. Sci. 2008, 63, 93-104.

36. Li, Y.F. Study on the eco-environmental changes in Sanjiang Plain during recent years. Environ. Sci. Manag. 2013, 38, 42-46.

37. Wang, C.Y.; Wu, Z.J.; Wang, R.Y. Soda-saline soil in the Sanjiang Plain of Heilongjiang Province. Chin. J. Soil Sci. 2001, 32, 23-25. (In Chinese)

38. Wang, X.; Zhang, G.; Xu, Y.J. Spatiotemporal groundwater recharge estimation for the largest rice production region in Sanjiang Plain, Northeast China. J. Water Supply Res. Technol. 2014, 63, 630-641. 
39. Drew, M.C.; Stolzy, L.H. Growth under oxygen stress. In Plant Roots: The Hidden Half; Waisel, Y., Eshel, A., Kafkafi, U., Eds.; Marcel Dekker: New York, NY, USA, 1996; pp. 363-381.

40. Drew, M.C. Oxygen deficiency and root metabolism: Injure and acclimation under hypoxia and anoxia. Annu. Rev. Plant Physiol. 1997, 48, 223-250.

41. Sorenson, S.K.; Dileanis, P.D.; Branson, F.A. Soil Water and Vegetation Responses to Precipitation and Changes in Depth to Ground Water in Owens Valley; USGS: Denwer, CA, USA, 1991.

42. Rengasamy, P.; Chittleborough, D.; Helyar, K. Root-Zone constraints and plant-based solutions for dryland salinity. Plant Soil 2003, 257, 249-260.

43. Bouwer, H. Artificial recharge of groundwater: Hydrogeology and engineering. Hydrogeol. J. 2002, 10, 121-142.

44. Lago, M.; Araujo, M. Capillary rise in porous media. J. Colloid Interface Sci. 2001, 234, 35-43.

45. Fries, N.; Dreyer, M. The transition from inertial to viscous flow in capillary rise. J. Colloid Interface Sci. 2008, 327, 125-128.

46. Averianov, S. Seepage from irrigation canals and its influence on regime of groundwater table. In Influence of Irrigation System on Regime of Ground Water; Academic Press, USSR: Moscow, The Soviet Union, 1956; pp. 140-151.

47. Chen, T.F.; Wang, X.S.; Li, H.; Jimmy, J.J.; Li, W. Redistribution of groundwater evapotranspiration and water table around a well field in an unconfined aquifer: A simplified analytical model. J. Hydrol. 2013, 495, 162-174.

48. Yu, Z.W. The Theory of Crop Planting: North Part; China Agriculture Press: Beijing, China, 2003. (In Chinese).

49. Ma, W.; Fang, J.; Yang, Y.; Mohammat, A. Biomass carbon stocks and their changes in Northern China's grasslands during 1982-2006. Sci. China Life Sci. 2010, 53, 841-850. (In Chinese)

50. Gardner, W.H. Some steady state solutions of the unsatuarated moisture flow equation with application to evaporation from a water table. Soil Sci. 1950, 85, 228-232.

51. Gardner, W.H. Calculation of capillary conductivity from pressure plate outflow date. Soil Sci. Soc. Am. Proc. 1956, 20, 317-320.

52. Hillel, D. Introduction to Soil Physics; Academic Press, Inc.: San Diego, CA, USA, 1982; p. 364.

53. Shah, N.; Nachabe, M.; Ross, M. Extinction depth and evapotranspiration from groundwater under selected land covers. Groundwater 2007, 45, 329-338.

(C) 2015 by the authors; licensee MDPI, Basel, Switzerland. This article is an open access article distributed under the terms and conditions of the Creative Commons Attribution license (http://creativecommons.org/licenses/by/4.0/). 